\title{
Los consorcios del sector público autonómico: naturaleza y características
}

\author{
Javier Ferreira Fernández \\ Profesor Titular de Derecho Administrativo \\ Universidad de Santiago de Compostela
}

Sumario: I. INTRODUCCIÓN. 1. El desarrollo de la fórmula consorcial en el ámbito autonómico 2. La colaboración interadministrativa y los consorcios.-II. EVOLUCIÓN NORMATIVA DE LOS CONSORCIOS: DEL CONSORCIO LOCAL A LOS CONSORCIOS AUTONÓMICOS. III. CRITERIOS PARA LA INTEGRACIÓN DE UN CONSORCIO EN EL SECTOR PÚBLICO AUTONÓMICO.1. Consorcios que no gestionan intereses comunes a diversos niveles de administración 2. Consorcios que gestionan intereses comunes a diversos niveles de administración. 2.1 Criterios normativos. 2.2. Propuesta de solución.-IV. CARACTERÍSTICAS DE LOS CONSORCIOS AUTONÓMICOS. 1. Carácter asociativo. 2. Carácter voluntario. 3. Heterogeneidad en su composición. 4. Personalidad jurídica propia e independiente. 5. Naturaleza jurídico-pública. 6. Carácter instrumental respecto de las Administraciones consorciadas. 7. Posición de dominio de la administración autonómica.- -V. UNA APROXIMACIÓN AL RÉGIMEN DE CONTRATACIÓN Y DE PERSONAL DE LOS CONSORCIOS AUTONÓMICOS. 1. Régimen de contratación. 2. Régimen de personal.

Resumen: La figura del consorcio interadministrativo, nacida de la mano de la normativa de régimen local, ha dado un gran salto evolutivo para situarse entre las entidades públicas instrumentales más emergentes del sector público autonómico. Sin embargo, la creciente presencia de los consorcios en el ámbito autonómico no ha supuesto una actualización de su régimen jurídico, siendo mayoría las Comunidades Autónomas que todavía no han procedido a la regulación normativa de esta figura. En el presente artículo se aborda el análisis de la evolución normativa de esta tipología de ente público adelantando, a la vista de la disparidad de criterios contenidos en la normativa autonómica comparada, una propuesta de regulación básica que armonice las reglas de adscripción de los consorcios al sector público de que se trate, con el fin de clarificar debidamente el régimen jurídico al que deberán quedar sometidos en el desarrollo de sus actividades y en su funcionamiento.

Palabras clave: Consorcio, entidades Locales, comunidades autónomas, administración instrumental. 


\begin{abstract}
The figure of the interadministrative consortium, been born from the hand of the norm of local regime, has been placed between the instrumental organizations of more success in the autonomic public sector. Nevertheless, the increasing presence of the consortia in the autonomic scope, has not originated the revision of its legal regime, being majority the Autonomous Regions that have still not come to the normative regulation of this figure. In the present article the normative evolution of this figure will be analyzed and that will advance, considering the disparity of existing criteria in the compared autonomic norm, a basic proposal of regulation to harmonize the rules of allegiance of the consortia to the corresponding public sector, in order to clarify the legal regime to which they will have to be put under in the development of their activities and their operation.
\end{abstract}

Keywords: Consortium, local governments, autonomous regions, instrumental administration.

\title{
I. INTRODUCCIÓN
}

\section{El desarrollo de la fórmula consorcial en el ámbito autonómico}

En el mes de enero del año 2006, tuvo lugar la firma del Acuerdo entre la Xunta de Galicia y la Federación Gallega de Municipios y Provincias por el que se establece el contenido y desarrollo del Pacto local que regirá en la Comunidad Autónoma de Galicia. Este Acuerdo, con el que Galicia se situaba a la cabeza del resto de Comunidades Autónomas en el proceso de segunda descentralización, establecía, en su apartado II A) que «la Xunta y la FEGAMP crearán, en el año 2006, el Consorcio Gallego de Servicios de Bienestar, al que podrán adherirse los municipios afectados, para la gestión conjunta de los centros de la red primaria: casas de juventud, casas del mar, escuelas infantiles, puntos de atención a la infancia y centros de día para la tercera edad».

La creación del Consorcio respondía a la necesidad de arbitrar una nueva fórmula de cooperación interadministrativa en una materia, como son los servicios sociales, en la que existe una responsabilidad compartida entre la Administración autonómica y la local². Además de buscar una mayor eficacia y eficiencia en la

1 Durante la legislatura 2005-2009, tuve la oportunidad de desempeñar el cargo de secretario general de la Vicepresidencia de la Igualdad y del Bienestar, Departamento de la Administración autonómica competente para la gestión de las políticas en materia de servicios sociales en la Comunidad Autónoma de Galicia, lo que me ha permitido conocer, de primera mano, el proceso de gestación y posterior desarrollo de esta nueva fórmula organizativa de gestión.

2 El Estatuto de Autonomía de Galicia, aprobado por Ley Orgánica 1/1981, de 6 de abril, atribuye a la Comunidad Autónoma gallega, en su artículo 27.23, competencia exclusiva en materia de asistencia social. Por su parte, la Ley 5/1997, de 22 de julio, de Administración Local de Galicia, establece, en su artículo 80.2, que los municipios gallegos ejercerán, en todo caso, competencias en los términos de la legislación del Estado y de la Comunidad Autónoma, en las siguientes materias (...) k) la prestación de servicios sociales y la promoción y reinserción sociales, configurando en su artículo 81, como servicio mínimo, la prestación de tales servicios en los ayuntamientos de más de 20.000 habitantes. 
prestación de servicios de primera necesidad para los ciudadanos, se hacía preciso superar el modelo tradicional de financiación de aquellos servicios sociales de ámbito municipal que tienen una clara incidencia supramunicipal (en particular Centros de Día y Escuelas infantiles) y que, en esa medida, también eran prestados por la propia administración autonómica, generando en ocasiones absurdas duplicidades.

Dicho modelo, basado en la convocatoria anual de subvenciones para la construcción y gestión de estos equipamientos, impedía una gestión racional de los mismos. Y ello, por diversas razones:

i) en primer lugar, por el alto grado de inejecución de las obras, servicios y/o actividades subvencionadas, con la consiguiente pérdida de fondos;

ii) en segundo lugar, por la notable inseguridad jurídica que supone para los perceptores de las subvenciones, que una vez puesto en marcha el servicio, desconocen si van a tener asegurados los recursos suficientes para su mantenimiento, lo que dificulta una planificación racional de su funcionamiento y extensión;

iii) en tercer lugar, por la notable precarización del empleo público generado en estos ámbitos, en la medida en que las retribuciones y la continuidad de este personal vienen determinados, en gran medida, por las ayudas que recibe el titular del servicio;

iv) en cuarto lugar, por la escasa capacidad para desarrollar una planificación territorial adecuada de las inversiones, que, en la mayor parte de los casos, queda al albur de la iniciativa individual del respectivo ayuntamiento;

v) y, por último, por la imposibilidad de aprovechar, lo que hoy se dan en llamar, las «sinergias» que una gestión en red de dichos servicios podría generar y que una gestión individualizada impide.

Estas fueron, principalmente, las razones que animaron al gobierno gallego a crear un Consorcio que sirviese de marco estable de colaboración en el ámbito de los servicios sociales. Un consorcio creado por el convenio 3 subscrito el 3 de julio de 2006 por la Xunta de Galicia y 14 ayuntamientos gallegos, y cuyos estatutos, que figuran anexados al mismo, atribuyen a la Administración autonómica una clara posición dominante en el proceso de toma de decisiones en el ámbito de los órganos rectores del Consorcio (el $51 \%$ de los votos totales en el seno de la Asamblea General y la mayoría de representantes -5 de 9 - en el Comité Directivo).

3 Publicado en el Diario Oficial de Galicia, número 131, de 7 de julio de 2006, mediante Resolución de 4 de julio de 2006, de la Secretaría General y de Relaciones Institucionales de la Vicepresidencia de la Igualdad y del Bienestar. 
A día de hoy, y en poco más de dos años de funcionamiento, forman parte de este Consorcio, junto a la Administración autonómica, un total de 265 entidades locales -entre ellas, 3 mancomunidades de municipios-, entre las que se encuentran seis de los siete municipios de gran población de Galicia. El 84\% de los municipios gallegos, que concentran el 90,5\% de la población (2,5 millones de personas), están integrados en este proyecto.

Este ente gestiona hoy más de 54 millones de euros de presupuesto (el 80,2\% procede de transferencias de la Xunta de Galicia; el 13,54\% de los precios públicos derivados de la prestación de servicios y, el 6,26\% restante, de las aportaciones de los municipios consorciados), siendo más de 1000 los puestos de trabajo que conforman el equipo profesional del conjunto de equipamientos gestionados por el Consorcio.

Ahora bien, más allá de los motivos a que se acaba de hacer mención, en la base del éxito de esta fórmula han estado, como en la mayor parte de las fórmulas asociativas, otras razones que rara vez asoman en la literatura jurídica y que, en mi opinión, inciden de modo determinante en el éxito o fracaso de procesos de esta naturaleza. Veámoslas:

i) En primer lugar, el incremento substancial de los fondos autonómicos destinados a estos fines; es decir, la aportación de mayores recursos por parte de la «administración promotora» resulta indispensable para garantizar el éxito. Como se acaba de decir, más del $80 \%$ de los fondos aportados al Consorcio proceden de la Xunta de Galicia. En el anterior modelo, dicha aportación (en forma de subvención), no alcanzaba el 70\% del coste de la obra o del servicio.

ii) En segundo lugar, la asunción por el nuevo ente de la gestión directa de los equipamientos y la consiguiente descarga de esta responsabilidad a los ayuntamientos integrados ha supuesto para ellos un notable alivio, sobre todo en el caso de los municipios más pequeños, si bien se les ha permitido mantener un elevado protagonismo político en dicha gestión (forman parte de los órganos de gobierno de los equipamientos, participan en los procesos de selección del personal y en los procesos de admisión de las personas usuarias).

iii) En tercer lugar, tal y como veremos seguidamente, la ausencia de un marco normativo constrictivo ha permitido una gestión mucho más ágil de los recursos, tanto humanos como materiales, eso sí, respetando los principios básicos de actuación de las administraciones públicas.

No obstante, ese notable vacío normativo ha provocado que, tanto en el procedimiento para su constitución, como en los aspectos relativos a la gestión ordinaria de sus actividades (particularmente en el ámbito del control presupuestario y de la gestión del personal), hayan surgido numerosos conflictos derivados, fundamental172 mente, de la indeterminación de la naturaleza jurídica de esta figura y de la impreci- 
sión de sus propios Estatutos. No es ésta una cuestión baladí, pues de la correcta determinación de su naturaleza, va a depender el régimen jurídico aplicable a sus actos (control financiero y presupuestario, régimen de personal, contratación, etc) ${ }^{4}$.

Ahora bien, el auge del fenómeno consorcial no es un fenómeno exclusivo de Galicia. Al contrario, el Consorcio es, hoy en día, la forma jurídica instrumental de mayor éxito en el ámbito autonómico, desbordando así su tradicional ámbito de actuación que era el estrictamente locals. Ello ha permitido que la misma tome carta de

$4 \quad$ Un ejemplo de esta incertidumbre y confusión es, en el caso gallego, la existencia, en el mismo Juzgado (JCA n. ${ }^{\circ} 2$ de Santiago de Compostela) de dos pronunciamientos absolutamente contradictorios sobre la naturaleza jurídica del Consorcio Gallego de Servicios de Igualdad y Bienestar. Nótese que es el mismo órgano jurisdiccional, el que en dos sentencias coincidentes en el tiempo ( 7 de mayo y 30 de julio de 2007), y ante supuestos de hecho idénticos, concluye, en uno y otro proceso, respectivamente, en la naturaleza jurídica autonómica y local del referido ente consorcial. Así, la primera de ellas (Sentencia de 7 de mayo de 2007) establece que «... el Texto Refundido de 1986 no ha querido caracterizar a todos los consorcios que puedan constituirse al amparo de su artículo 110 como entidades locales, pero sin negarles tampoco tal consideración, permitiendo que en cada caso, según las circunstancias concurrentes, pueda determinarse si el consorcio constituido es o no una entidad local, no existiendo razones para atribuir esta naturaleza al consorcio que nos ocupa. Si se examina el artículo 3 de los estatutos del consorcio, debe concluirse que tiene la condición de entidad de derecho público, de carácter interadministrativo y por ello que las funciones que se le atribuyen al Consorcio no constituyen una competencia propia de los entes locales, que se encuentra atribuida a los municipios como así se deduce de la lectura del artículo 6 que establece los fines generales del consorcio... ». Por el contrario, la Sentencia de 30 de julio de 2007 , concluye en que «no estamos en este caso en presencia de un convenio de colaboración entre órganos administrativos de la Administración General del Estado o de organismos públicos vinculados o dependientes de ella y órganos administrativos correspondientes de las Administraciones autónomas, sino ante un convenio de colaboración entre la Administración local y la Administración autonómica que encaja en los sistemas de cooperación regulados en los artículos 57 y 87.1 de la Ley 7/1985, de 2 de abril, reguladora de las Bases de Régimen Local, y 110 del Real Decreto Legislativo 781/1986, de 18 de abril, por el que se aprueba el TRRL. (... ) En cuanto al régimen jurídico por el que se rige la actividad y funcionamiento del Consorcio, es el artículo 3.2 de los estatutos el que hace mención a su carácter voluntario, y a su constitución por tiempo indefinido, disponiendo que se regirá por sus estatutos, por su reglamento de régimen interno y por las demás disposiciones legales que, para el efecto, se enumeran en el artículo primero de estos estatutos, y demás disposiciones que, por la naturaleza del ente consorcial, le resulten de aplicación. Es por ello por lo que al margen de la consideración que pueda merecer o no el consorcio demandado como ente local, lo cierto es que son sus propios estatutos los que se remiten a la Ley 7/1985, como norma que integra el conjunto de disposiciones legales por las que debe regirse, al decir que el consorcio se constituye de conformidad con la Ley 30/1992, el Real Decreto Legislativo 2/2004, de 5 de marzo y la Ley $7 / 1985$, de 2 de abril».

5 Según los datos del Directorio de Entes del Sector Público Autonómico (datos publicados por el Ministerio de Economía y Hacienda, a fecha 1 de enero de 2009), del total de entes existentes en el conjunto de las Comunidades Autónomas (1940), el 30\% aproximadamente (573), son Consorcios, mientras que las sociedades mercantiles representan un $27 \%$ del total, las fundaciones un $20 \%$, los entes públicos un $10 \%$ y los Organismos Autónomos un 9\%.

Las Comunidades Autónomas en las que los consorcios tienen mayor peso específico en el conjunto de los entes integrantes del sector público son:

- Andalucía: el 48,3\% (144 de un total de 298).

- Cataluña: el 44,4\% (143 de un total de 322).

- Baleares: el 61,1\% (99 de un total de 162).

Además, a lo largo de los últimos 5 años se han creado más de 100 nuevos consorcios, frente a la creación de 80 sociedades y 46 entes de derecho público de diversa naturaleza.

En Galicia, figuran 21 consorcios sobre un total de 144 entidades integrantes del Sector público autonómico; dato que no coincide con los manejados por la propia Comunidad Autónoma (un total de 11), lo 
naturaleza dentro del sector público autonómico, tal y como ha reconocido el propio legislador ${ }^{6}$. En la mayoría de las ocasiones son las Comunidades Autónomas quienes promueven su creación y quienes se garantizan una clara posición de dominio, tanto orgánico como financiero. Posición de dominio que, en ocasiones, desfigura la propia naturaleza consorcial o paccionada de la figura, por cuanto son las propias Comunidades Autónomas las que los utilizan como un ente instrumental más.

En mi opinión, entre las diversas razones que han determinado el espectacular incremento de los Consorcios 7 , se pueden destacar las siguientes: i) el mencionado vacío normativo que ha hecho del Consorcio una institución extraordinariamente dúctil y adaptable a las más diversas circunstancias (son mayoría todavía las Comunidades Autónomas que no han procedido a la regulación normativa de los consorcios autonómicos); ii) el estrepitoso fracaso de otras fórmulas asociativas, singularmente en el ámbito local; iii) la cada vez más perentoria necesidad de acudir a fórmulas de colaboración vertical para facilitar las relaciones interadministrativas en un estado complejo con tres niveles autónomos de decisión, y donde la incertidumbre es la nota característica del reparto competencial, cuestión a la que me referiré seguidamente; iv) y, por qué no decirlo, un cierto efecto mimético, bastante frecuente en nuestro estado autonómico.

Se trata, por lo demás, de un desarrollo que ha venido determinado por dos notas características: la espontaneidad y falta de planificación de su creación (ésta nunca ha respondido a una decisión racional y planificada previamente) y la ausencia de un marco normativo definido. Notas que, por lo demás, han acompañado, en general, el desarrollo de la administración instrumental española ${ }^{8}$. A ello podría añadirse el escaso interés doctrinal que ha despertado, por el momento, este tipo de entes 9 .

que evidencia la utilización de criterios dispares a la hora de determinar la adscripción de los entes consorciales a una u otra Administración y confirma, en definitiva, la nebulosa que pesa sobre la determinación de la naturaleza jurídica de estos entes.

En todo caso, hay que señalar que el $90 \%$ de los consorcios autonómicos citados están integrados también por entes locales, dato éste que viene a poner de manifiesto que el aspecto puramente subjetivo de la integración de una entidad local en un consorcio no resulta determinante de su naturaleza local.

6 Vid. Apartado II del presente artículo.

7 Según los datos del Directorio de Entes del Sector Público Autonómico publicados por el Ministerio de Economía y Hacienda con fecha 1 de enero de 2009, a finales del año 2003 existía en el conjunto del Estado un total de 464 consorcios autonómicos, cifra que en tan solo cinco años se ha incrementado en un $23,4 \%$ (109 nuevos consorcios autonómicos).

8 Vid. en general sobre esta cuestión Navajas Rebollar, M. (2000) La nueva administración instrumental. Madrid: Colex. Un ejemplo reciente del desarrollo desordenado de este tipo de entes en el ámbito autonómico nos lo muestra Almeida Cerreda, M. (2009) Los Entes instrumentales en la Administración autonómica gallega. Análisis de su régimen jurídico y propuestas para la reforma de la normativa estatutaria y legal vigente. Trabajo de investigación pendiente de publicación.

9 La mayor parte de los estudios sobre el consorcio se han centrado en los consorcios locales, siendo muy limitadas las referencias a los consorcios de ámbito autonómico. Entre los estudios clásicos sobre los consorcios locales pueden destacarse las obras de Martínez López-Muñiz (1974) Los Consorcios en el Derecho español -Análisis de su naturaleza jurídica. Madrid: IEAL y Martín Mateo, R (1971) «Los consorcios 


\section{La colaboración interadministrativa y los consorcios}

De todas las razones que he señalado como base del éxito de esta figura, la más relevante, jurídicamente hablando, es la de servir de vehículo para la colaboración entre los diversos niveles territoriales que conforman nuestro Estado ${ }^{10}$.

Es una opinión común que la configuración de un Estado fuertemente descentralizado como el que ha diseñado la Constitución Española de 1978, exige, necesariamente, la consolidación de una cultura de cooperación y/o colaboración entre los distintos entes que lo integran.

Todo ello se hace más necesario, si cabe, si tenemos en cuenta la notable dificultad para deslindar espacios o ámbitos competenciales de carácter exclusivo ${ }^{11}$. Esta característica, común al ámbito de actuación de las Comunidades Autónomas y del Estado $^{12}$, resulta más evidente en el caso de la delimitación de competencias de los entes locales.

(1987) Entes locales complejos. Madrid: Trivium, y Martín Mateo, R (1992) «Los Consorcios locales: una institución en auge». RAP, 129: 8 y ss.;:López Menudo, $\mathrm{F}$ (1995) «Servicios municipales y gestión consorciada» en Pedro Escribano Collado (Coord) Jornadas de Estudios sobre consorcios locales: Temas de Administración Local. Ediciones Adhara, S.L.. 1-34. Castillo Blanco, F (1991) «Los consorcios de entidades locales: análisis y evolución a la luz de la nueva legislación de régimen Local» RAP, 124: 397 y ss. Castillo Blanco, F (2001) "Los Consorcios Administrativos: especial referencia a los consorcios de entidades locales en la legislación andaluza», Revista Andaluza de Administración Pública, 42: 95 y ss; Nieto Garrido, E. (1997) El Consorcio Administrativo, Barcelona: Cedecs. Barrero Domínguez, C. (2002) «Los conceptos de mancomunidades y consorcios: necesidad de delimitación y diferenciaciones». Revista Andaluza de Administración Pública, 45: 81 y ss. $y$ Rebollo Puig, M. (1997) «Los Consorcios entre entes locales como forma de cooperación», en Anuario del Gobierno Local.1997. Madrid: Marcial Pons: 203 y ss.

10 Véase Barrero Domínguez, C. (2002), op. cit. p. 109.

11 Como ha afirmado Almeida Cerreda, M. (2009) «Las relaciones interadministrativas: las relaciones de colaboración, control y conflicto», artículo pendiente de publicación. «la existencia de una pluralidad de administraciones públicas que, constitucionalmente, tienen garantizada su autonomía implica que, a cada una de ellas, el ordenamiento jurídico les confiere determinadas funciones y potestades para el logro de concretos y específicos fines de interés de la colectividad social de referencia de las mismas, pero la distribución teórica y técnica de dichas funciones y potestades efectuada por el Ordenamiento nunca es perfecta y ello es así porque no siempre es posible deslindar exhaustivamente sobre una misma realidad fáctica (personal y territorial) los intereses de cada concreta colectividad territorial que muchas veces, inevitablemente se entrecruzan; surgiendo, en consecuencia, superposiciones de ámbitos competenciales o vacíos competenciales. En definitiva, la autonomía reconocida a las diferentes Administraciones públicas sobre la base de la necesariamente imperfecta distribución competencial se traduce, en la práctica, por una parte, en una fuerte tendencia de dichas Administraciones a la actuación independiente para la consecución de sus particulares fines, sin consideración de los objetivos de interés público perseguidos por las demás y, por otra parte, al conflicto por la defensa de los respectivos ámbitos de actuación».

12 En este sentido, García de Enterría, E y Fernández Rodríguez, T.R. (2006) Curso de Derecho Administrativo. Tomo I. Madrid, 13 ed.: Civitas han entendido que la «colaboración» puede ser el único remedio a la «esquizofrenia jurídica» que supone la superposición de ordenamientos sobre un mismo ámbito o materia. Para ellos, refiriéndose a las relaciones entre el ordenamiento estatal y autonómico, «resulta inexcusable que sobre esa identidad sustancial de ámbito territorial y subjetivo de aplicación de los dos ordenamientos éstos tengan que tenerse mutuamente en cuenta y trabajar, en tal sentido, alguna relación positiva de colaboración; sin ésta, los destinatarios comunes, tanto los ciudadanos como los tribunales que en una única organización (arts. 117.5, 122.1 y 2 y 152.1 de la Constitución) han de aplicar uno y otro Derecho, como la Administración 
En efecto, de una lectura detallada de los artículos 25 y 26 de la Ley $7 / 1985$, de 2 de abril, reguladora de las Bases del Régimen Local, puede advertirse la práctica inexistencia de ámbitos competenciales realmente exclusivos, existiendo, en la mayor parte de los supuestos, una superposición con las competencias que atribuyen a las Comunidades Autónomas los respectivos Estatutos de Autonomía13.

Como ha puesto de manifiesto la Comisión encargada de la redacción del Libro Blanco para la Reforma del Gobierno Local, «la legislación básica de régimen local no ofrece una lista determinada y formal de competencias locales, efectuando una remisión a las leyes sectoriales estatales y autonómicas, que serán las llamadas a atribuir competencias, limitándose la ley básica a establecer una serie de materias de interés local (artículo 25). Esta remisión no ha obtenido un resultado satisfactorio por varias razones. En primer lugar, porque en algunas ocasiones las leyes sectoriales ni siquiera han atribuido competencias a los gobiernos locales o han devuelto la remisión a lo que disponga la legislación sobre régimen local, efectuando así lo que ha sido calificado como remisión diabólica en la que resultan olvidados los gobiernos locales. Pero es fácilmente constatable que cuando las competencias han sido reconocidas, el contenido atribuido dista mucho de llenar la expectativa de la autonomía local. (...) Existen otros casos en los que el contenido atribuido no pasa de meras facultades gestoras, sin una relevancia que permita hablar de auténticas competencias. Es decir, no se atribuye un verdadero campo competencial que permita a los gobiernos locales desarrollar las políticas públicas que bajo su propia responsabilidad decidan implementar en su territorio» ${ }^{14}$.

ejecutora de ambos, que veremos que es también la misma en una parte sustancial, podrían verse forzados a una suerte de esquizofrenia jurídica, en el sentido clínico riguroso del término esquizofrenia, esto es, a un desdoblamiento o fraccionamiento de la personalidad en función del ordenamiento que les afecte, que pueden ser, ciertamente, los dos, incluso respecto de una misma, indivisible, situación social o de hecho, o incluso en el seno de la misma relación jurídica. Ello es mucho más obligado aún ante un Estado social de Derecho, con una actividad prestacional e interventora o reguladora generalizada».

13 El artículo 25 de la LBRL establece que el municipio, para la gestión de sus intereses y en el ámbito de sus competencias, puede promover toda clase de actividades y prestar cuantos servicios públicos contribuyan a satisfacer las necesidades y aspiraciones de la comunidad vecinal. En su apartado segundo, dicho precepto determina el elenco de materias sobre las que, en todo caso, los municipios deberán ejercer competencias. Así, entre ellas, la seguridad en lugares públicos, ordenación del tráfico de vehículos y personas en las vías urbanas, protección civil, prevención y extinción de incendios; protección del medio ambiente, prestación de los servicios sociales y de promoción y reinserción social, suministro de agua y alumbrado público, etc.. Los términos del ejercicio de las competencias municipales sobre las materias citadas se establecerán en la legislación del Estado y de las Comunidades Autónomas, operando como límite de la distribución legal de competencias municipales las previsiones contenidas en el artículo 26 de la citada Ley. A estos efectos, la regulación autonómica de los sectores de actividad relacionados, en la práctica totalidad de los supuestos, configura un mapa competencial compartido entre la propia Comunidad Autónoma y los municipios en el que siempre se suele dar entrada a la primera, aunque sólo sea a título de planificación u ordenación de la actividad de que se trate. Así por ejemplo, mientras el artículo 26 de la LBRL establece que corresponde a los municipios de más de 20.000 habitantes, por si o asociados, la prestación, entre otros, de servicios sociales, la recientemente aprobada Ley 13/2008, de 3 de diciembre, de Servicios sociales de Galicia -dictada en desarrollo del artículo 27.23 del Estatuto de Autonomía de Galicia- establece que el ejercicio de las competencias municipales -previstas, a estos efectos, en el artículo 60 de la citada Ley-, se realizará, en todo caso, en el marco de la planificación y ordenación general del Sistema gallego de servicios sociales que corresponde, en todo caso, a la Administración autonómica.

14 Ministerio de Administraciones Públicas (2005) Libro Blanco para la Reforma del Gobierno Local.

176 Madrid: Secretaría de Estado de Cooperación Territorial., 46-47. 
Es así como del ámbito privativo de competencias locales que, aparentemente, había garantizado la Ley básica de 1985, hemos pasado a la realidad de un amplio espacio competencial compartido por los entes locales y las Comunidades Autónomas, que, indefectiblemente, debe conducir, por mandato constitucional, a una estrecha colaboración.

El propio Tribunal Constitucional ha reconocido, entre otras, en su Sentencia 27/1987, de 2 de marzo, la necesidad constitucional de establecer cauces de relación interadministrativa en el ejercicio de las competencias que para la gestión de sus respectivos intereses corresponden a las diferentes Administraciones Públicas. Para él, «dado que cada organización es una parte del todo, no cabe deducir de la Constitución que, en todo caso, corresponda a cada una de ellas un derecho o facultad que le permita ejercer las competencias que le son propias en régimen de estricta y absoluta separación. Por el contrario, la unidad misma del sistema en su conjunto, en el que las diferentes entidades autónomas se integran, así como el principio de eficacia administrativa (art. 103.1 de la C.E.), que debe predicarse no sólo de cada Administración Pública, sino del entero entramado de los servicios públicos, permiten, cuando no imponen, al legislador establecer fórmulas y cauces de relación entre unas y otras Administraciones locales y de todas ellas con el Estado y las Comunidades Autónomas, en el ejercicio de las competencias que para la gestión de sus intereses respectivos les correspondan».

Es así como la figura del Consorcio cobra una verdadera relevancia constitucional en tanto que instrumento apto, como veremos, para la implementación de un marco estable de cooperación y colaboración entre las diferentes Administraciones en la realización de aquellas actividades o servicios que revistan un interés común a todas ellas, garantizando con ello una mayor eficacia y eficiencia en la gestión de los asuntos públicos ${ }^{15}$.

\section{EVOLUCIÓN NORMATIVA DE LOS CONSORCIOS: DEL CONSORCIO LOCAL A LOS CONSORCIOS AUTONÓMICOS}

Desde una perspectiva jurídica, el Consorcio ha vivido un proceso evolutivo en el que pueden distinguirse tres fases:

15 En el mismo sentido Castillo Blanco, F. (2001), op. cit. p. 100, ha destacado que «en el caso español, si atendemos a los elementos actuales que definen la actuación de nuestras Administraciones Públicas, resulta aún, si cabe, más evidente lo hasta ahora expuesto. Basta repasar serenamente los artículos 148 y 149 del texto constitucional, los artículos 25 y siguientes de la Ley $7 / 85$, de 2 de abril, Reguladora de las Bases de Régimen Local, para comprobar que no existen apenas ámbitos competenciales de prestación de servicios a los ciudadanos que correspondan en exclusiva a alguna Administración Pública (precisamente por ello asistimos no hace mucho tiempo al debate sobre la «Administración Única»), sino que, muy por el contrario, se produce un solapamiento de competencias entre las diversas Administraciones Públicas que no hace sino avalar la idea de la necesidad de racionalizar el efectivo ejercicio de las competencias legal y constitucionalmente atribuidas, haciendo surgir, cuando los intereses sean comunes, entidades asociativas de las que el Consorcio pudiera ser el paradigma que hagan a su vez efectivos los principios de solidaridad y cooperación y eviten, de una vez por todas la funesta duplicidad de organizaciones que realicen una misma labor, con los indudables efectos de dispersión de iniciativas, de descoordinación y de mayor gasto público que ello comporta». 
i) La primera fase se caracteriza por la consideración del consorcio como un ente local o un ente asociativo para la defensa de intereses locales.

En efecto, la primera regulación general del Consorcio se recoge en el Reglamento de Servicios de las Corporaciones Locales, aprobado por Decreto de 17 de junio de 1955. En su artículo 37, la referida norma establece que «las Corporaciones Locales podrán constituir consorcios con Entidades Públicas de diferente orden con el fin de instalar o gestionar servicios de interés local». Sin reconocer expresamente su carácter de entidad local, lo cierto es que el Tribunal Supremo le reconoció tal carácter desde su propio nacimiento ${ }^{16}$.

Más tarde, las Bases del Estatuto de Régimen Local (Ley 41/1975, de 19 de noviembre ${ }^{17}$ ) reconocen ya a esta figura como una entidad local, condición que se confirmó en el Texto articulado parcial de 6 de octubre de $1977^{18}$.

ii) La segunda fase, que se puede situar entre los años 1985 y 2000, se caracteriza por la superación de la calificación del consorcio como entidad local y por su consideración como un ente asociativo para la gestión de «intereses comunes», singu-

16 En su Sentencia de 2 de abril de 1979, el Tribunal Supremo estableció que «con el nacimiento del Consorcio surge un nuevo Ente Local, dotado de personalidad jurídica, como ya se anticipó, del que se ha dicho que es una asociación de Asociaciones, una asociación local de segundo grado, un Ente instrumental, servido por técnicas de colaboración y de articulación de competencias públicas, es obvio que las funciones o servicios a desarrollar por el mismo, a él tienen que ser imputables, y, en ese ajuste de competencias se produzca una metamorfosis, desapareciendo las originarias de los Entes integrados, para reinar las atribuidas al Consorcio, que, por carecer de población y territorio propios, lo que en él aparece como elemento identificador es la función o servicio que haya servido de causa generatriz (...)»

17 En su Base 39, relativa a la Organización administrativa se establece: «Uno. Las Entidades Locales podrán crear, modificar o suprimir los órganos de gestión administrativa no representativos, necesarios para el desarrollo de las actividades a su cargo, dentro de los niveles y tipos de orrganización establecidos por el ordenamiento local. Dos. Para el desarrollo de los servicios a su cargo, las Entidades Locales están facultadas para crear personas jurídicas que podrán revestir la forma de fundación pública o análogas; constituir Sociedades con limitación de responsabilidad, suscribiendo la totalidad del capital o con participación de otros entes públicos, así como establecer Sociedades de economía mixta. Tres. Igualmente podrán las Entidades Locales utilizar formas indirectas de gestión para los servicios que les están encomendados. Los servicios que impliquen ejercicio de autoridad habrán de prestarse en régimen de gestión directa. Cuatro. Las Entidades Locales, en la forma que se establezca, poderán constituir consorcios con Entidades Públicas de diferente orden o naturaleza, para fines de interés para las respectivas poblaciones. Los consorcios gozarán de personalidad jurídica propia y de la consideración de Entidades Locales. Cinco. La actividad de las Entidades Locales podrá sujetarse a plan o programa».

18 El Real Decreto 3046/1977, de 6 de octubre, por el que se articula parcialmente la Ley 41/1975, de Bases del Estatuto de Régimen Local, en lo relativo a los Funcionarios Públicos Locales y otros extremos, establece, en su artículo 107, que «1. Las Entidades Locales podrán constituir consorcios con entidades públicas de diferente orden o naturaleza para fines de interés para las respectivas poblaciones. 2. Los consorcios gozarán de personalidad jurídica propia y de la consideración de entidades locales. 3. Los Estatutos de los consorcios, que serán aprobados por el Consejo de Ministros a propuesta del Ministerio del Interior y previo Dictamen del Consejo de Estado, determinarán los fines del Consorcio, así como las particularidades del régimen orgánico, funcional y financiero, en relación con el general de las Entidades Locales. 4. Sus órganos de decisión estarán integrados por representantes de todas las entidades públicas consorciadas, en la proporción que se fije en los estatutos respectivos. 5. Podrán utilizar para la gestión de los servicios de su competencia, cualesquiera de las formas previstas en la legislación de régimen local» 
larmente de los entes locales y de las Comunidades Autónomas. En esta fase, el consorcio va a ser reconocido, aunque tangencialmente, no sólo por las normas de régimen local, sino también por las generales de régimen jurídico de las administraciones públicas, aunque sin definir con precisión su singular naturaleza jurídica.

Así, con la entrada en vigor de la Ley $7 / 1985$, de 2 de abril, Reguladora de las Bases del Régimen Local (LBRL) se inicia el proceso de desvinculación de la figura del consorcio interadministrativo del estricto ámbito de los intereses locales, para pasar al ámbito de los intereses comunes ${ }^{19}$. No puede olvidarse que la LBRL fue aprobada una vez creadas todas las Comunidades Autónomas que, como ya hemos dicho, van a asumir o compartir una parte sustancial de lo que eran tradicionalmente espacios privativos de actuación de los entes locales. Esta ley regula directa o indirectamente el consorcio en diversos preceptos:

En primer lugar, el artículo 3 de la LBRL no incluye, de forma deliberada, entre las entidades locales a los consorcios interadministrativos ${ }^{20}$.

En segundo lugar, el artículo 57 establece que la cooperación económica, técnica y administrativa entre la Administración Local y las Administraciones del Estado y de las Comunidades Autónomas, tanto en servicios locales como en asuntos de interés común, se desarrollará con carácter voluntario, bajo las formas y en los términos previstos en las Leyes, pudiendo tener lugar, en todo caso, mediante los consorcios o convenios administrativos que subscriban. El consorcio se configura así como un instrumento de cooperación interadministrativa en el que podrán participar diferentes

19 Castillo Blanco, F. (1991) op. cit. p. 408, apoya esta misma tesis al poner el acento, como nota característica de la figura consorcial, en la presencia de intereses públicos comunes a las Administraciones consorciadas; intereses que, en este supuesto, no serán exclusivamente municipales, a diferencia de lo que acontece en las mancomunidades de municipios. En el mismo sentido, Barrero Domínguez, C. (2002), op. cit. pp. 109-110. Una opinión diferente es la mantenida por Martín Mateo, R. (1987) op. cit., p. 112, para quien «a pesar de todo creemos que el régimen real del Consorcio no ha sufrido alteraciones sustanciales con la nueva legislación y que siguen siendo Entidades Locales, aunque de carácter derivativo y no simplemente entidades de naturaleza singular que no forman parte de la Administración Local, como se ha afirmado con escaso esfuerzo caracterizador, por cierto».

20 Con esta forma de proceder, resulta obvio que el legislador básico estatal no ha querido configurar, con carácter necesario, a la totalidad de consorcios que puedan constituirse a su amparo como entidades locales. Prueba de ello es que las diversas enmiendas presentadas durante la tramitación parlamentaria del Proyecto de Ley que proponían su caracterización como ente local, fueron rechazadas. En efecto, esta disyuntiva se planteó con la presentación, por los Grupos parlamentarios popular y centrista, de sendas enmiendas al Proyecto de Ley citado con la finalidad de que el texto definitivamente aprobado por la Cámara incluyese, en la dicción literal de su artículo 3, a los consorcios como entidades locales. (Vid. Diario de Sesiones del Congreso, núm. 122, de 18 de octubre de 1984). Este debate se retoma en el año 2003, con ocasión de la tramitación parlamentaria del Proyecto de Ley de Medidas para la Modernización del Gobierno Local. En este caso, es el Grupo Parlamentario Vasco quien, a través de la enmienda n. ${ }^{\circ} 125$ al proyecto de Ley citado, solicita la inclusión de los consorcios en la relación de entidades locales del artículo 3.2 de la Ley 7/1985, de 2 de abril. La enmienda fue nuevamente rechazada (por 164 votos en contra, 33 a favor y 92 abstenciones), al entender la Comisión de Régimen de las Administraciones Públicas (Vid. Diario de Sesiones del Congreso, núm. 825, de 30 de septiembre de 2003) que los consorcios podían constituirse igualmente con personas jurídicas que no tuviesen la condición de entidad local. 
Administraciones Públicas (y, en su caso, entidades privadas sin ánimo de lucro), no sólo para la prestación de servicios puramente locales, en los que el interés local resulta, como es lógico, subyacente, sino también en asuntos que resulten de interés común a las diferentes entidades consorciadas.

Por último, el artículo 87 reconoce, en el ámbito de las actividades y servicios de las corporaciones locales, la posibilidad que asiste a éstas para constituir consorcios con otras Administraciones Públicas para el desarrollo de fines de interés común, o con entidades sin ánimo de lucro que persigan fines de interés público, concurrentes con los de las Administraciones Públicas.

Por su parte, el artículo 110 del Real Decreto Legislativo 781/1986, de 18 de abril, por el que se aprueba el Texto Refundido de las Disposiciones Legales Vigentes en materia de Régimen Local, reitera lo previsto en la LBRL, añadiendo dos nuevas previsiones: en primer lugar, que corresponderá a los estatutos determinar los fines del consorcio, así como las particularidades de su régimen orgánico, funcional y financiero, en segundo lugar, que sus órganos de decisión estarán integrados por representantes de todas las entidades consorciadas, en la proporción que se fije en los Estatutos respectivos.

No será hasta la aprobación de la Ley 30/1992, de 26 de noviembre, de Régimen Jurídico de las Administraciones Públicas y del Procedimiento Administrativo Común (LAP) cuando se reconozca, por primera vez en el ámbito estatal, y al margen de la legislación de régimen local, la figura del consorcio interadministrativo.

Inicialmente en su artículo 7, y, tras la reforma operada por la Ley 4/1999, de 13 de enero, en su artículo 6.5, la LAP reconoce a los consorcios como una manifestación del principio de colaboración interadministrativa. Este artículo prevé que cuando la gestión de un convenio entre Administraciones haga necesario crear una organización común, ésta podrá adoptar la forma de consorcio dotado de personalidad jurídica o sociedad mercantil, encomendándose a los estatutos del consorcio la determinación de sus fines, así como las particularidades de su régimen orgánico, funcional y financiero. Además, la Ley establece que los órganos de decisión estarán integrados por representantes de todas las entidades consorciadas, en la proporción que se fije en la norma estatutaria, pudiendo utilizarse, para la gestión de los servicios que se le encomienden, cualquiera de las formas previstas en la legislación aplicable a las Administraciones consorciadas.

El hecho de que el referido precepto únicamente cite, refiriéndose al ámbito subjetivo de los convenios de colaboración, a la Administración General del Estado y a las Administraciones de las Comunidades Autónomas, unido a la remisión a la normativa básica local en todo lo relativo a las relaciones interadministrativas con las entidades locales (art. 9), ha llevado a algunos autores a concluir que, en estos casos, no sería posible la participación de una entidad local en los consorcios creados a su

180 amparo y, de ahí, a entender que existen dos regímenes jurídicos diferentes, el de los 
consorcios con participación de entes locales (entidades locales) y el de aquellos en que no hay tal participación (entidades no locales) ${ }^{21}$.

En mi opinión, dicha remisión no supone en modo alguno el establecimiento de dos regímenes diferenciados, no sólo porque entre ambas regulaciones no existen diferencias sustanciales, sino también porque la aplicación supletoria de los preceptos de la LAP sirve para limar las posibles diferencias o carencias de la LBRL (por ejemplo, en todo lo relativo a la posibilidad de que el Consorcio sea fruto de un Convenio) y, en esa medida, para dotar de mayor homogeneidad a esta regulación. Además, no debe olvidarse que ni la LAP, ni la LBRL establecen en ninguno de sus preceptos cuál ha de ser el régimen jurídico aplicable ni la administración a la que han de adscribirse los Consorcios, participen en ellos entes locales o no. Así lo ha entendido el propio Tribunal Supremo en diversos pronunciamientos ${ }^{22}$.

En definitiva, la existencia de una previsión normativa diferente para los consorcios participados por entes locales, responde, en mi opinión, a una simple opción de

21 Para Castillo Blanco, F. (2001), op. cit., pp. 119-120 «aún cuando parecería coherente que la legislación básica de régimen jurídico fuese aplicable a todas las figuras consorciales, no parece esa la solución adoptada. En efecto, si repasamos la figura consorcial que aparece en el art. 6 LRJPAC (en la redacción ofrecida por la Ley 4/1999), y paradójicamente a pesar del carácter básico de la misma, han de destacarse los siguientes aspectos (...) El artículo 9 de la Ley añade, confirmando lo ya adelantado unas líneas más arriba, que las relaciones entre la Administración General del Estado y las Administraciones de las Comunidades Autónomas con las entidades que integran la Administración local se regirán por la legislación básica de régimen local, siendo aplicable supletoriamente lo dispuesto en dicho título, lo que en principio parecería excluir de la citada regulación prevista en el artículo 6 a los entes locales». En el mismo sentido Pérez Torrente (1996) ha afirmado que «Como fácilmente se advierte, el artículo 7 de la Ley regula tan sólo el régimen de consorcios entre el Estado y las Comunidades Autónomas. La Ley de bases de régimen local y el texto refundido de 1986 regularían los consorcios en que participaran entidades locales. Así pues, la Ley 30/1992, en lugar de crear una regla común, consagra dos regímenes que en más de una ocasión serán distintos. Ratifica esta conclusión el artículo 9 de la Ley 30/1992, el cual, bajo el epígrafe de «relaciones la Administración Local» dispone lo siguiente: «las relaciones entre la Administración general del Estado o la Administración de la comunidad autónoma con las entidades que integran su Administración local se regirán por la legislación básica en materia de régimen local.»» «Los Consorcios». Revista Catalana de Derecho Público. 21: 52-65.

22 Para el Alto Tribunal (Sentencia de 2 de junio de 2001), «desde el año 1997 se ha venido consagrando la tesis que permitía salir a los consorcios del reducido ámbito de la consideración como un ente local, creado por los ayuntamientos ex reglamento mencionado, (RSCL) al reconocer la personalidad propia de un consorcio integrado por una pluralidad de entes más amplia, tales como una Confederación Hidrográfica, una Diputación Provincial y diversos municipios. Posteriormente, la Ley 30/1992, de 26 de noviembre, de Régimen Jurídico de las Administraciones Públicas y del Procedimiento Administrativo Común, rescató legislativamente a esta figura de su estrecho encierro, haciendo de ella, con carácter general, una aplicación del principio de colaboración entre las Administraciones Públicas, al disponer, en su artículo 6.5 que, cuando la gestión de un convenio entre Administraciones, «haga necesario crear una organización común, ésta podrá adoptar la forma de consorcio, dotado de personalidad jurídica o sociedad mercantil». Desde entonces -sigue diciendo el TS- su evolución ha sido imparable, siempre de la mano de su independencia de cualquier Administración y de su afirmación como ente con personalidad propia». Para acabar afirmando que «Lo expuesto confirma la independencia conceptual y organizativa del consorcio y del ayuntamiento y la improcedencia de la tesis de la entidad recurrente», que entendía que el Consorcio era una entidad local, por ser creado al amparo de la LBRL. En un sentido similar, vid. SSTS de 3 de noviembre de 1997 y de 30 de abril de 1999. 
técnica normativa, consistente en no reiterar o reproducir en el texto general de la LAP lo que, con carácter especial, ya regula para los entes locales la LBRL. En todo caso, una regulación común a todas ellas en la propia LAP hubiese evitado el debate surgido con ocasión de la redacción del artículo 9 citado. Por cierto, debate que no se ha planteado, en ningún caso, en los tribunales, quienes, con total normalidad y escasa justificación, han llegado a admitir la constitución de consorcios de muy diversa naturaleza, con base en lo previsto en la LAP ${ }^{23}$.

Al igual que ha ocurrido en el ámbito estatal, en el ámbito autonómico han sido las normas de régimen local las que han regulado primeramente los Consorcios.

1) En primer lugar están las Comunidades Autónomas que como consecuencia de la influencia de una legislación estatal ya superada, sólo regulan en sus leyes de régimen local los consorcios que tienen la condición de entidades locales, sometidos, en consecuencia, a la legislación local en los aspectos relativos a su organización y funcionamiento. Éste es el caso de la Ley 5/1997, de 22 de julio, de Administración Local de Galicia (arts. 149 y siguientes) o la Ley $20 / 2006$, de 15 de diciembre, municipal y de régimen local de las Islas Baleares (art. 2).

2) En un segundo grupo están aquellas Comunidades Autónomas que, siguiendo el espíritu de la LBRL, aprovechan la legislación local para regular la integración de las entidades locales en todo tipo de consorcios, tengan o no carácter de entidad local. Así, el Reglamento de Obras, Actividades y Servicios de las Entidades Locales de Cataluña, aprobado por Decreto 179/1995, de 13 de junio, regula los consorcios en los que, al menos, se integre una administración local, remitiendo a la norma estatutaria la determinación de su naturaleza (arts. 312.2 y 316.1.c). Por su parte, la Ley 7/1993, de 27 de julio, de Demarcación Municipal de Andalucía, se limita a establecer que los consorcios podrán constituirse entre entidades locales y cualquier otra Administración Pública o entidad privada sin ánimo de lucro para la realización de actuaciones conjuntas, la coordinación de actividades y la consecución de fines de interés común, debiendo someter su actuación al derecho administrativo (art. 35). En similares términos se manifiesta la Ley 7/1999, de 9 de abril, de Administración Local de Aragón (arts. 218 y 219).

3) Por último, la única norma autonómica que hasta el momento, y al margen de la regulación de régimen local, prevé expresamente la posibilidad de constituir consorcios en el ámbito autonómico, adelantándose incluso al legislador básico estatal, es la Ley 13/1989, de 14 de diciembre, de organiza-

23 Por ejemplo, en Sentencia de 8 de octubre de 2007 el Tribunal Superior de Justicia de Madrid no se cuestiona la validez de un consorcio creado ex artículo 7 de la Ley 30/1992 (nuevo artículo 6.5 tras la reforma de la Ley 4/1999, de 13 de enero) entre la Comunidad Autónoma de Madrid y una Cámara de Comercio, Industria y Navegación. 
ción, procedimiento y régimen jurídico de la Administración de la Generalitat de Cataluña. En su artículo 55, la referida Ley habilita al gobierno autonómico a acordar la constitución de consorcios entre la Generalitat y otras administraciones públicas para finalidades de interés común o con entidades privadas sin ánimo de lucro que tengan finalidades de interés público concurrentes con las de la Administración.

iii) La tercera fase, desde el año 2000 hasta hoy, se define por el extraordinario desarrollo de la figura consorcial en el ámbito autonómico y por la necesidad de poner límite a un proceso de generación casi espontánea que ha alcanzado un nivel preocupante, sobre todo en términos de control presupuestario. Normativamente hablando, esta fase se caracteriza porque los consorcios van a ser objeto de tratamiento en las normas presupuestarias y financieras estatales y autonómicas, con el fin de poner límite a su proceso de expansión incontrolada y de determinar su adscripción a algún sector público (estatal, autonómico o local), a efectos, fundamentalmente, de control financiero. También es en esta fase cuando comienzan a aparecer pronunciamientos judiciales en los que, mayoritariamente, se aborda la cuestión de la naturaleza de los consorcios a efectos de precisar cuáles hayan de ser las normas aplicables en materia de personal (sobre todo respecto del desarrollo de las funciones de secretaría o intervención y, en particular, si éstas han de estar reservadas a funcionarios con habilitación de carácter estatal), así como el procedimiento de constitución a seguir.

Así, si hasta el año 2000 «el legislador no había sometido aún rígidamente la organización y régimen del consorcio a los tipos legalmente preestablecidos» ${ }^{24}$ el espectacular crecimiento de los entes consorciales a finales de los años 90, unido a la necesidad de disciplinar presupuestariamente a todo el sector público con el fin de garantizar los objetivos de estabilidad presupuestaria, le llevó a tomar conciencia de su existencia y a tratar de clarificar su naturaleza jurídica y régimen de adscripción, al igual que antes había ocurrido con otros entes instrumentales.

La Ley 47/2003, de 26 de noviembre, General Presupuestaria, con el fin de precisar qué debe entenderse por entes integrantes del sector público estatal, a efectos de control financiero y de cumplimiento de los principios de estabilidad presupuestaria, ha previsto por primera vez en nuestro ordenamiento, de forma explícita, consorcios que no tienen naturaleza local, al establecer, en su artículo 2, que formarán parte del sector público estatal «Los consorcios dotados de personalidad jurídica propia a los que se refieren los artículos 6, apartado 5, de la Ley 30/1992, de 26 de noviembre, de Régimen Jurídico de las Administraciones Públicas y del Procedimiento Administrativo Común, y 87 de la Ley 7/1985, de 2 de abril, reguladora de las Bases del Régimen Local, cuando uno o varios de los sujetos enumerados en este artículo (entes integrantes del sector público estatal) hayan aportado mayoritaria-

24 Vid. STS de 3 de noviembre de 1997. 
mente a los mismos dinero, bienes o industria, o se hayan comprometido, en el momento de su constitución, a financiar mayoritariamente dicho ente y siempre que sus actos estén sujetos directa o indirectamente al poder de decisión de un órgano del Estado».

Será también a partir del año 2000 cuando se despierte la preocupación del legislador autonómico por el tratamiento y, en su caso, control (en el proceso de creación y desde el punto de vista financiero y presupuestario) de estos entes públicos, de igual forma que había hecho el legislador estatal.

Así, la última generación de normas autonómicas sobre finanzas públicas (Decreto Legislativo 1/2000, de 29 de junio por el que se aprueba el Texto Refundido de la Ley de Hacienda Foral de la Comunidad Autónoma de Aragón, Ley 14/2006, de 24 de octubre de Finanzas de Cantabria, Ley 2/2006, de 3 de mayo de Hacienda y del Sector Público de Castilla y León, Ley 11/2006, de 11 de diciembre de Hacienda de Canarias y Ley 5/2007, de 19 de abril, de Hacienda de Extremadura) contempla ya los requisitos de adscripción de los consorcios al sector público autonómico a los efectos de determinar el régimen de control financiero.

En ocasiones, las menos, serán las normas reguladoras de la Administración Pública autonómica las que determinen esta adscripción, considerando de aplicación a los consorcios integrados en el sector público autonómico el ordenamiento jurídico propio de la Comunidad Autónoma de que se trate. Es el caso de las Leyes 3/2003, de 26 de marzo, de Régimen de la Administración de las Islas Baleares, 15/2004, de 3 de diciembre, de la Administración Foral de Navarra o 9/2007, de 22 de octubre, de Administración de la Junta de Andalucía.

\section{CRITERIOS PARA LA INTEGRACIÓN DE UN CONSORCIO EN EL SECTOR PÚBLICO AUTONÓMICO}

La cuestión que a continuación ha de resolverse es la de la determinación de la naturaleza jurídica de esta figura, y en particular, cuáles han de ser las «circunstancias concurrentes» que, en palabras del propio Tribunal Supremo ${ }^{25}$, deberán darse para adscribir un consorcio al sector público local, autonómico o estatal.

Se trata de una cuestión de especial relevancia por cuanto la adscripción del consorcio al sector público de que se trate, será determinante del régimen jurídico al que deberá quedar sometido en el desarrollo de sus actividades y en su funcionamiento, contribuirá a evitar fenómenos de huida del derecho administrativo, en particular, los controles derivados del régimen financiero y presupuestario aplicables al resto de las entidades integrantes del sector público y, además, contribuirá a evitar los fenóme-

25 Vid. STS de 30 de abril de 1999. FJ 3. 
nos de doble adscripción o de «apatridia» derivados de la indefinición de criterios actualmente existente ${ }^{26}$.

\section{Consorcios que no gestionan intereses comunes a diversos niveles de administración}

Sin entrar a valorar ahora la idoneidad de la figura consorcial para supuestos de "consorcios locales puros», esto es, consorcios integrados exclusivamente por entes locales para el desarrollo de competencias o servicios locales tal y como prevén algunas leyes autonómicas, parece evidente, habida cuenta de la homogeneidad de los entes que lo integran y de los fines que se persiguen, que en estos casos el consorcio tendrá naturaleza local ${ }^{27}$.

En mi opinión, la naturaleza local del ente tampoco quebraría, en aquellos consorcios creados con el único fin de gestionar servicios de competencia exclusiva local, por el hecho de que se integrase en el mismo una Administración de distinto nivel.

Ello es así, porque, como ha declarado el Tribunal Supremo (entre otras, en la Sentencia de 3 de abril de 1998), la cooperación no puede articularse afectando a competencias propias, o con el fin de desapoderar a los entes titulares de las mismas. Para él, opinión que comparto, «aún sin estar recogida en el texto constitucional, la colaboración y cooperación de las distintas Administraciones Públicas forman parte del sistema como elemento inherente, según ha señalado el Tribunal Constitucional en Sentencia 18/1982, de 4 de mayo, pero ninguna de sus manifestaciones puede producirse con infracción de los postulados constitucionales, y los condicionamientos impuestos por el propio ordenamiento jurídico, especialmente en lo que se refiere al diseño de las respectivas competencias que puede verse afectado cuando se establecen mecanismos que resulten contrarios a la propia autonomía. Y ello es así tanto en lo que se refiere al art. 57 LRBRL, relativo a los consorcios y convenios administrativos como instrumentos de cooperación económica, técnica y administrativa entre las distintas Administraciones (Local, del Estado y de las Comunidades Autónomas), como en las manifestaciones específicas o mecanismos típicos de cooperación $(. . .)^{28}$ ».

26 Como ya se apuntó anteriormente, según los Datos del Directorio de Entes del Sector Público Autonómico a fecha 1 de enero de 2009, publicados por el Ministerio de Economía y Hacienda, en Galicia, figuran 21 consorcios sobre un total de 144 entidades integrantes del Sector público autonómico; dato que no coincide con los manejados por la propia Comunidad Autónoma que solo incluye 11, lo que evidencia la utilización de criterios dispares a la hora de determinar la adscripción de los entes consorciales a una u otra Administración.

27 Vid. Rebollo Puig, M. (1997), op. cit., p. 206.

28 Vid, en el mismo sentido la STS de 3 de abril de 1999, la STSJ de Valencia de 30 de junio de 2008 o la STSJ de Castilla y León de 3 de mayo de 2002. En todas ellas se mantiene la naturaleza local de los consorcios en cuestión, participados por la Comunidad Autónoma y entidades locales con el único fin de gestionar servicios de competencia exclusiva de éstas. Esta misma tesis es compartida por Castillo Blanco, F (2001), op. cit., pp. 95 a 99. 
Así pues, en el hipotético caso de que en un consorcio constituido para la gestión de intereses puramente locales el control efectivo en los procesos de toma de decisiones y, por ende, la dirección funcional del mismo, correspondiese a una Administración distinta de la local, se estaría procediendo a un verdadero vaciamiento de competencias municipales contrario, como afirma el Tribunal Supremo, al principio constitucional de autonomía local. A la misma conclusión cabría llegar en el hipotético supuesto de que los servicios gestionados fuesen de competencia exclusiva de una Comunidad Autónoma o del Estado.

En definitiva, siempre que un Consorcio gestione competencias o servicios atribuidos en exclusiva a una administración pública y en el que no haya gestión alguna de intereses comunes, ésta deberá mantener la dirección funcional del mismo. En otro caso, su constitución devendría nula, por contravenir el orden constitucional y legal de reparto de competencias.

\section{Consorcios que gestionan intereses comunes a diversos niveles de administración}

\subsection{Criterios normativos}

Así pues, la problemática de la determinación de la naturaleza jurídica queda reducida a los consorcios que podríamos denominar «mixtos». Mixtos desde el punto de vista subjetivo y mixtos desde el punto de vista competencial. Esta es la naturaleza de la mayoría de los consorcios existentes, dirigidos a facilitar la colaboración entre diversas administraciones públicas en la defensa de sus intereses comunes.

Como hemos visto, ni la LAP, ni la LBRL precisan la naturaleza jurídica de estos consorcios interadministrativos.

Ante el silencio del legislador, la doctrina ha mantenido posiciones divergentes. Para Rebollo Puig, en estos casos serán los estatutos del Consorcio los que deberán precisar su naturaleza, teniendo en cuenta para ello su composición y las actividades o servicios a desarrollar ${ }^{29}$. Para Martín Mateo, en un Consorcio participado por la Administración del Estado o de las Comunidades Autónomas y las administraciones locales, corresponderá a los estatutos determinar su régimen jurídico y, en caso de silencio de la norma estatutaria, habrá de estarse al control establecido en cuanto al funcionamiento de sus órganos rectores o a los fines prevalentes del Consorcio ${ }^{30}$. Por

29 En opinión de este autor, «el propósito -refiriéndose a la regulación contenida en el TRRL por contraposición a la prevista en el Texto articulado parcial de 6 de octubre de 1977- es justamente no imponer que el régimen aplicable a los consorcios sea siempre el de las administraciones locales y permitir que, en función de la composición y actividades del consorcio, los estatutos partan de proclamar, según los casos, un sometimiento general al derecho de la Administración local, o al de la estatal o autonómica». Rebollo Puig, M. (1997), op. cit., p. 249.

30 En su opinión, "Si como consideramos que se ha demostrado, los consorcios son entes de derecho público, gestionadores de actividades de interés local, parece lógico concluir, como resultado del 
último, Nieto Garrido, partiendo de un elemento inalterable, cual es la naturaleza de derecho público de los entes consorciales, sostiene que la naturaleza jurídica del consorcio interadministrativo vendrá determinada por el dato de cuál es la Administración que ostente el control efectivo de sus órganos de gobierno31.

No obstante, y como ya he dicho, será a partir del año 2000 cuando, como consecuencia de la aparición de un importante número de consorcios, el legislador mostrará una especial preocupación por esta cuestión. De un examen de las diversas leyes reguladoras del sector público estatal y autonómico, se advierte igualmente la inexistencia de criterios uniformes sobre la adscripción de los consorcios.

1) En primer lugar, están las normas que exigen para la adscripción de un consorcio la concurrencia simultánea de una posición de control orgánico y financiero por parte de la administración a la que se adscriben.

Así ocurre para la delimitación de los consorcios integrados en el sector público estatal ${ }^{32}$ y de los consorcios integrados en el sector público autonómico de Castilla y León, Canarias y Extremadura ${ }^{33}$. En estos casos, cuando uno o varios de los entes integrantes del sector público estatal o autonómico citados, hayan aportado mayoritariamente al consorcio dinero, bienes o industria, o se hayan comprometido, en el mo-

sumatorio de este polinomio caracterológico, que estaremos en presencia de una entidad local». No obstante, el autor admite la posibilidad de desvirtuar esta deducción «ante la presencia de un factor de signo negativo, a saber, la expresa remisión de los estatutos a otro ordenamiento con pérdida de control por parte de las Entidades locales de los órganos del consorcio a favor de otras AAPP o de entidades privadas». «La presencia del Estado o de las CCAA en un consorcio en el que participan también entes locales -continúa el citado autor- no es por sí misma definitoria de su régimen jurídico. Habrá que estar a lo que digan los correspondientes estatutos y, en caso de silencio, al control establecido en cuanto al funcionamiento de sus órganos rectores, o a los fines prevalentes del Consorcio. Si los estatutos, aunque no opten por un determinado bloque ordenamental, son suficientemente explícitos en cuanto al régimen económico y de toma de decisiones, puede no ser tan perturbador la ausencia de precisiones normativas en otro nivel». Martín Mateo R (1992). «Los consorcios Locales. Una Institución en Auge». Revista Galega de Administración Pública. 0: 25-36.

31 «El consorcio administrativo - dice esta autora- tendrá la naturaleza jurídica de ente local cuando el control efectivo de sus órganos de gobierno lo ostenten entidades locales territoriales. En este supuesto, los Estatutos de la entidad serán completados, en su caso, con las disposiciones de régimen local que rigen la vida de los entes locales. Sin embargo, la naturaleza jurídica de ente local no puede afirmarse respecto de aquellos entes en los que el control efectivo de sus órganos de gobierno corresponde a la CCAA o, incluso, al Estado. El régimen jurídico aplicable a estas entidades no se corresponde con el de los entes locales, sino con el de la CCAA de referencia o, en su caso, con el del Estado. En este supuesto se integran los consorcios constituidos al amparo de la regulación contenida en el artículo 7 LAP. En definitiva, el consorcio administrativo tiene actualmente naturaleza de ente de derecho público y su régimen jurídico es, por ende, igualmente, público. No obstante, las particularidades que establezcan los estatutos de la entidad se encuadran en el régimen jurídico aplicable a la misma que variará en función de la naturaleza de los entes-miembros que ejerzan el control efectivo sobre los órganos de gobierno del consorcio (en su caso, entidades locales, la CCAA o el Estado)». Nieto Garrido, E. (1997), p. 123.

32 Artículo $2.1 \mathrm{~h}$ de la Ley 43/2007, de 26 de noviembre, General Presupuestaria.

33 Artículo $1 \mathrm{f}$ ) de la Ley $2 / 2006$, de 2 de mayo, de Hacienda y Sector Público de Castilla y León; artículo 2 g) de la Ley 11/2006, de 11 de diciembre, de Hacienda de Canarias y artículo 2.1 h) de la Ley 5/2007, de 19 de abril, de Hacienda de Extremadura. 
mento de su constitución, a financiar mayoritariamente dicho ente y siempre que sus actos estén sujetos directa o indirectamente al poder de decisión de un órgano del Estado o de las citadas Comunidades Autónomas, el Consorcio formará parte del sector público de aquéllos ${ }^{34}$.

2) En segundo lugar, están las normas que determinan la adscripción por la concurrencia alternativa de una posición de control orgánico o de control financiero por parte de la administración a quien se adscriben.

Este es el caso de la Ley 14/2006, de 24 de octubre, de Finanzas de Cantabria que define a los consorcios dependientes del sector público autonómico como aquellos en los que uno o varios de los sujetos pertenecientes al sector público hayan participado en su financiación en un porcentaje igual o superior al 50\%35, o se hayan comprometido, en el momento de su constitución, a financiar mayoritariamente dicha entidad o sus actos estén sujetos directa o indirectamente al poder de decisión de un órgano de la Comunidad Autónoma.

Del mismo modo, la Ley 15/2004, de 3 de diciembre, de la Administración de la Comunidad Foral de Navarra establece que «los consorcios financiados mayoritariamente por la Administración de la Comunidad Foral, o aquellos en los que corresponda a ésta la designación de más de la mitad de los miembros de sus órganos de decisión, han de someter su organización y actividad al ordenamiento jurídico propio de la Comunidad Foral de Navarra» ${ }^{36}$, criterio que acoge en similares términos la Ley

34 Esta adscripción, no obstante, no está exenta de problemas interpretativos. Así, estas normas no precisan cuándo existe financiación mayoritaria, y, en particular, si la misma debe ser permanente o estable. Es por ello que una financiación mayoritaria inicial, si no va aparejada de una financiación mayoritaria continuada, no debiera poder determinar la permanencia del consorcio en el sector público de que se trate.

En relación con la concurrencia del requisito del poder de decisión de la Administración estatal y/o de las administraciones autonómicas citadas en sus actos, cabría entender que la sujeción de los actos del consorcio al poder de decisión de la Administración de que se trate ha de implicar la existencia de una posición de dominio que determine, de facto, el control efectivo en el proceso de toma de decisiones, lo que, sin embargo, no se afirma expresamente. A estos efectos será necesario tener en cuenta diferentes factores, como son la composición de sus órganos de gobierno y/o la configuración del sistema de mayorías para la adopción de acuerdos y la formulación de propuestas. En este sentido, el Real Decreto 1463/2007, de 2 de noviembre, por el que se aprueba el Reglamento de Desarrollo de la Ley 18/2001, de 12 de diciembre, de Estabilidad Presupuestaria en su aplicación a las Entidades Locales (artículo $2.1 \mathrm{f}$ ), considera que éstas ostentan una posición de dominio sobre los consorcios en los que participen (consorcios, por tanto, integrados en el sector público local), cuando: a) dispongan de mayoría de votos en los órganos de gobierno, o b) tengan facultades para nombrar o destituir a la mayoría de los miembros del órgano de gobierno.

35 Resulta cuestionable que la simple participación de un ente integrante del sector público autonómico en un porcentaje de financiación igual al 50\% resulte determinante de la adscripción del mismo, por cuanto tal participación puede no derivar en un efectivo control del ente consorcial y por tanto de sus decisiones (pensemos, por ejemplo, en un consorcio participado paritariamente, en términos de porcentaje de financiación, por la Comunidad Autónoma y por otra Administración Pública).

36 Nótese que la Ley navarra sustituye el requisito del poder de decisión por el de la designación, por la Administración autonómica, de la mayoría de miembros en los órganos rectores del consorcio. En todo caso, la simple facultad de designación de la mayoría de miembros en los órganos de gobierno del Consorcio no determina, necesariamente, el ejercicio de una posición dominante en el proceso de toma de 
3/2003, de 26 de marzo, de Régimen de la Administración de las Islas Baleares. Por su parte, la Ley 9/2007, de 22 de octubre, de Administración de la Junta de Andalucía, acoge un criterio triple: a) la aportación mayoritaria de dinero, bienes o industria, b) el compromiso, en el momento de constitución del consorcio, de financiación mayoritaria, c) la designación por parte de la Administración de la Junta de Andalucía de más de la mitad de los miembros de sus órganos de dirección. En cualquiera de estos supuestos, resultará de aplicación a los consorcios autonómicos el régimen económico-financiero, de control y contabilidad establecido en la Ley General de la Hacienda Pública de la Comunidad Autónoma de Andalucía. En este mismo grupo podría incluirse el Decreto 217/2008, de 25 de septiembre de la Xunta de Galicia, por cuanto establece que formarán parte del sector público autonómico los consorcios cuando el proyecto de acuerdo por el que se autoriza la participación de la Xunta de Galicia o de alguno de los sujetos enumerados en su artículo 2 (organismos autónomos, entidades de derecho público vinculadas o dependientes, agencias públicas autonómicas, sociedades mercantiles públicas, fundaciones del sector público autonómico) prevea aportaciones mayoritarias o reserve la designación de más de la mitad de los miembros del órgano de gobierno a alguna de ellas ${ }^{37}$. Previsión que merece las mismas consideraciones apuntadas anteriormente.

3) En tercer y último lugar, están las Comunidades Autónomas que utilizan un único criterio de adscripción. En esta línea, y utilizando un criterio excesivamente impreciso, la Ley 3/2003, de 3 de marzo, del Sector Público de la Rioja, define a los consorcios integrados en el sector público autonómico como «aquellos en los que la posición mayoritaria en la Junta de Gobierno corresponda, directa o indirectamente, al gobierno de La Rioja». En términos semejantes, y con la misma imprecisión, el Texto Refundido de la Ley de Hacienda de la Comunidad Autónoma de Aragón (Decreto Legislativo 1/2000, de 29 de junio) utiliza el único criterio de la representación mayoritaria, directa o indirecta, de la Administración de la Comunidad Autónoma ${ }^{38}$.

decisiones. Esto sólo ocurrirá en aquellos sistemas ordinarios de voto, en los que existe una correspondencia entre el número de votos y el número de representantes, no así en los sistemas de voto ponderado. En todo caso, habrá que tener en cuenta no sólo el sistema de representación, sino el régimen de adopción de acuerdos en el seno de cada uno de los órganos colegiados, pues si la norma estatutaria impone la adopción de acuerdos por unanimidad o por una mayoría reforzada, la mayor representación personal no determinará, en ningún caso, la detentación de una posición de dominio.

37 Así, si la referida norma, a los efectos de la reglamentación del procedimiento de creación de los entes integrantes del sector público autonómico, parece sentar los criterios determinantes de la adscripción de los consorcios al sector público gallego, la Ley 3/2009, de 23 de junio, por la que se modifica, en su artículo 48, el Texto Refundido de la Ley de Régimen Financiero y Presupuestario de Galicia, rechaza acoger el mismo criterio, remitiéndose, a estos efectos, a los requisitos determinados por el sistema europeo de cuentas (SEC-95). Así, y según la referida Ley, integrarán los presupuestos de la Comunidad Autónoma (... g) los presupuestos de los consorcios en los que concurran los requisitos determinados por el sistema europeo de cuentas para integrarse en el sector de la Administración Pública Autonómica de Galicia. Sin embargo, lo que las normas SEC-95 establecen, en cualquier caso, son los criterios determinantes de la integración de tales entes en el sistema de contabilidad pública, no los criterios determinantes de su calificación como entes integrantes del sector público de que se trate.

38 En ambos supuestos se plantea el mismo problema, al no establecerse los criterios de medición de la representación mayoritaria (número de representantes o número de votos). En todo caso, y como 


\subsection{Propuesta de solución}

De acuerdo con lo dicho en el apartado anterior, puede apreciarse que tanto las Administraciones autonómicas como la Administración general del Estado adoptan criterios divergentes y, en ocasiones, contradictorios, susceptibles de generar conflictos de adscripción de los diferentes consorcios a una u otra Administración Pública. Así, por ejemplo, en las Comunidades Autónomas que adoptan, al igual que el Estado, un sistema de adscripción simultáneo (sistema de control orgánico y financiero) podrán generarse supuestos de falta de adscripción (consorcios sin dueño), particularmente en aquellos supuestos en los que ambas administraciones, estatal y autonómica, compartan esa posición de dominio (financiero, unas, y orgánico otras). De igual modo, si se produjera una modificación de la Ley General Presupuestaria en el sentido de incorporar un criterio de adscripción alternativo, podría producirse una ampliación de los consorcios integrados en el sector público estatal, ampliación que podría yuxtaponerse con los criterios de pertenencia regulados en las normas autonómicas. Por esta vía, dos normas producidas válidamente al amparo de sus sistemas jurídicos de fuentes, llegarían a reconocer que una misma entidad consorciada depende, a la vez, de dos sectores públicos diferentes, generando, con toda seguridad, un innecesario conflicto ${ }^{39}$.

Ante esta situación caótica, el único esfuerzo armonizador en la delimitación de los criterios de adscripción de los consorcios al sector público se ha dado en el marco de la legislación básica en materia de estabilidad presupuestaria.

Con este fin se aprobó el Real Decreto Legislativo 2/2007, de 28 de diciembre, por el que se aprueba el Texto Refundido de la Ley General de Estabilidad Presupuestaria cuyo objeto es «el establecimiento de los principios rectores a los que deberá adecuarse la política presupuestaria del sector público en orden a la consecución de la estabilidad y crecimiento económicos, en el marco de la Unión Económica y Monetaria, así como la determinación de los procedimientos necesarios para la aplicación efectiva del principio de estabilidad presupuestaria, de acuerdo con los principios derivados del Pacto de Estabilidad y Crecimiento, y en virtud de la competencia del Estado respecto de las bases y coordinación de la planificación general de la actividad económica». A estos efectos, y con el fin de garantizar la formación y el mantenimiento de un Inventario de Entes integrantes del Sector Público, que vele por la efectiva aplicación de este importantísimo principio, el legislador básico estatal, ha fijado los criterios determinantes de la adscripción de los consorcios al sector público estatal y local.

antes se puso de manifiesto, ninguno de estos criterios será determinante de la posición de dominio de la Comunidad Autónoma en el proceso de toma de decisiones (cfr. sistemas de voto ponderado y/o existencia de regímenes de votación por mayorías reforzadas).

39 Vid. Garcés Sanagustín, M. (2007) «El control Económico-Financiero de los Consorcios: Tendencias y Alternativas». IGAE, 19: 15-23. 
Como se dijo, según la LGP formarán parte del sector público estatal, «los consorcios dotados de personalidad jurídica propia a los que se refieren los artículos 6 , apartado 5, de la Ley 30/1992, de 26 de noviembre, de Régimen Jurídico de las Administraciones Públicas y del Procedimiento Administrativo Común, y 87 de la Ley $7 / 1985$, de 2 de abril, reguladora de las Bases del Régimen Local, cuando uno o varios de los sujetos enumerados en este artículo hayan aportado mayoritariamente a los mismos dinero, bienes o industria, o se haya comprometido, en el momento de su constitución, a financiar mayoritariamente dicho ente y siempre que sus actos estén sujetos directa o indirectamente al poder de decisión de un órgano del Estado» (art. 2.1.h). Por otra parte, y de conformidad con el artículo $2.1 \mathrm{f}$ ) del Real Decreto 1463/2007, de 2 de noviembre por el que se aprueba el Reglamento de desarrollo de la Ley 18/2001, de 12 de diciembre, de Estabilidad Presupuestaria, en su aplicación a las Entidades Locales, formarán parte del sector público local los consorcios que las entidades locales hayan podido constituir con otras administraciones públicas para fines de interés común o con entidades privadas que persigan fines de interés general, siempre que la participación (habrá que entender financiera) de la o las entidades locales en dichos Consorcios sea mayoritaria, o bien que en caso de igualdad de participación con otras entidades que no sean de carácter local, se cumpla alguna de las siguientes características: que la o las entidades locales dispongan de mayoría de votos en los órganos de gobierno; y que la o las entidades locales tengan facultades para nombrar o destituir a la mayoría de los miembros del órgano de gobierno.

Respecto del sector público autonómico, la legislación estatal sobre estabilidad presupuestaria ha encomendado al Consejo de Política Fiscal y Financiera (CPFF) la determinación de tales criterios. En los acuerdos adoptados en su reunión de 10 de abril de 2003, el CPFF delimita las entidades que, a los efectos del Inventario General, han de considerarse integradas en el sector público autonómico (así, los consorcios que las Comunidades Autónomas hayan podido constituir con otras Administraciones Públicas para fines de interés común o con entidades privadas sin ánimo de lucro que persigan fines de interés general); sin embargo omite la fijación de los requisitos necesarios para delimitar esta figura.

En consecuencia, los consorcios que no hayan podido adscribirse al sector público estatal o local según los criterios determinados en la Ley General Presupuestaria y en el Reglamento de desarrollo de la Ley 18/2001, de 12 de diciembre, de Estabilidad Presupuestaria, en su aplicación a las Entidades Locales, serán clasificados como entes integrantes del sector público autonómico. Criterio que no coincide, como es evidente, con los criterios de delimitación utilizados por cada una de las Comunidades Autónomas en su normativa específica.

Llegados a este punto, y teniendo presente la insostenibilidad de la situación actual, llena de contradicciones y lagunas, aún en aquellos ámbitos, como el de la estabilidad presupuestaria, en donde se ha hecho un mínimo esfuerzo de sistematización, parece evidente la necesidad de avanzar en la fijación de algún criterio bási- 
co que clarifique la adscripción de esta figura al sector público estatal, autonómico y local.

En mi opinión, ha de ser en la LAP, en tanto norma básica de organización y funcionamiento de las diversas administraciones públicas, en donde se fije dicho criterio. Así, al igual que la ley básica de régimen jurídico de las administraciones públicas y la de régimen local han fijado reglas generales para la creación de los consorcios, así como el contenido de sus Estatutos, entiendo que nada obsta para que, de igual modo, se fijen en ellas las reglas básicas de adscripción de los mismos, cuestión que, por las razones que se acaban de exponer, desborda el ámbito estricto de las competencias autonómicas y, en particular, de su potestad autoorganizatoria.

En este sentido, el Tribunal Constitucional, en su Sentencia 50/1999, de 6 de abril, ha afirmado que «la competencia relativa a la libre organización de la propia Administración autonómica (...) en tanto que competencia exclusiva tiene como único contenido la potestad para crear, modificar o suprimir los órganos, unidades administrativas o entidades que configuran las respectivas Administraciones autonómicas o dependen de ellas. (... ) Fuera de este ámbito de actividad autonómica exclusiva, el Estado puede establecer, desde la competencia sobre bases del régimen jurídico de las Administraciones Públicas del art. 149.1.18 CE, principios y reglas básicas sobre aspectos organizativos y de funcionamiento de todas las Administraciones Públicas. Esto significa, en palabras de la STC 227/1988, que la potestad organizatoria (autonómica) para determinar el régimen jurídico de la organización y funcionamiento de su propia Administración, no tiene carácter exclusivo, sino que debe respetar y en su caso desarrollar las bases establecidas por el Estado. En definitiva, salvo en lo relativo a la creación de la propia Administración, la potestad de autoorganización, incluso en lo que afecta a los aspectos de organización y de funcionamiento, no puede incluirse en la competencia exclusiva de autoorganización de las Comunidades Autónomas (...)».

A la vista de lo previsto ya en la normativa presupuestaria, creo que la solución más armónica ha de ser la de atender al criterio del control efectivo desde el punto de vista orgánico y financiero. Así, si las normas de régimen financiero y presupuestario someten la actividad económica del consorcio a los controles internos de la Administración General del Estado, de la Comunidad Autónoma o de las entidades que integran la Administración Local con base en estos criterios, resultaría absurdo y distorsionador aplicar unas normas diferentes a las aplicables al sector público estatal, autonómico o local en otras materias como en el régimen patrimonial o de personal.

Lo relevante a estos efectos es pues determinar quién tiene el poder decisión y, por tanto, el poder de conformar, directa o indirectamente, la voluntad del consorcio.

Parece evidente que, como señala LGP, este poder lo tiene quien simultánea192 mente haya aportado mayoritariamente al consorcio dinero, bienes o industria, o 
se haya comprometido, en el momento de su constitución, a financiar mayoritariamente dicho ente y siempre que sus actos estén sujetos directa o indirectamente al poder de decisión de un órgano de la misma. El establecimiento, con carácter básico, de un doble criterio de adscripción (la exigencia simultánea de un dominio orgánico y financiero), ofrece todas las garantías, en la medida en que de esta forma queda claramente definida la posición de dominio de la Administración de adscripción.

Es pues éste el criterio que, en mi opinión, y con carácter general debe trasladarse a la LAP, entendiendo para ello por poder de decisión la mayoría de votos en los órganos de gobierno o las facultades para nombrar o destituir a la mayoría de los miembros del órgano de gobierno.

¿Qué hacer en los demás casos? Es decir, ¿a quién se adscribe un consorcio cuando sólo concurre uno de los criterios? En mi opinión y teniendo en cuenta la importancia que en estos entes tiene el libre pacto asociativo con base en el cual se crean y que se expresa, fundamentalmente, en los Estatutos que se otorgan, deberán ser éstos quienes determinen dicha adscripción, de igual modo que ocurre con los fines, competencias, régimen organizativo, etc. En todo caso, esta adscripción, que debe realizarse a la luz de las circunstancias concretas concurrentes en el Consorcio, deberá hacerse, eso sí, teniendo en cuenta alguno de los criterios señalados, esto es, la presencia de algún elemento (control financiero u orgánico) que revele un especial poder de decisión de la administración a quien se adscribe. En caso de que esto no ocurra (supuesto bastante infrecuente por cuanto en sólo un 10\% de los casos, los entes integrantes de los consorcios tienen igual participación) serán los entes integrados quienes, en función de los criterios que consideren oportunos, determinarán qué normas les serán de aplicación y a qué administración se les debe considerar adscritos a efectos de control.

En todo caso, la norma básica deberá exigir de forma preceptiva el pronunciamiento de los Estatutos de los consorcios sobre esta cuestión, teniendo en cuenta, eso sí, los criterios que acabo de exponer. Cualquier otra solución aboca a una situación de indefinición intolerable en nuestro Estado de Derecho, por contradecir abiertamente el principio de seguridad jurídica.

\section{CARACTERÍSTICAS DE LOS CONSORCIOS AUTONÓMICOS}

Podemos entender por consorcios del sector público autonómico los entes de derecho público, de carácter instrumental y de base asociativa, con personalidad jurídica propia y diferente de los entes que lo integran, creados por la Administración autonómica y otras administraciones públicas y, en su caso, entidades sin ánimo de lucro, para el desarrollo de actividades de interés común a todas ellas, y en los que la Administración autonómica ostenta una posición dominante desde el punto de vista financiero y orgánico. 
De acuerdo con esta definición, los consorcios autonómicos vendrán definidos por las siguientes características, que describiré brevemente

\section{Carácter asociativo}

Se trata de una característica asumida por la totalidad de la doctrina ${ }^{40}$. En el caso de los consorcios autonómicos dicha asociación lo será de entes públicos de diferente naturaleza y nivel, en la que participa necesariamente una Comunidad Autónoma o un ente dependiente de ella, y en la que podrán participar, en su caso, entidades privadas sin ánimo de lucro que persigan fines de interés público concurrentes con los de las Administraciones Públicas.

\section{Carácter voluntario}

La voluntariedad es una nota esencial inherente a la propia naturaleza del consorcio interadministrativo. Tanto la normativa reguladora del régimen local como la LAP, facultan a las diferentes Administraciones Públicas para su creación, y enmarcan a los consorcios en el ámbito de las relaciones de colaboración y/o cooperación interadministrativa. A estos efectos, para su efectiva creación, será necesaria una concurrencia de voluntades, normalmente reflejada a través de un instrumento de carácter convencional. De ahí que los consorcios no puedan ser creados por Ley o norma de inferior rango, salvo que se acredite fehacientemente, y con carácter previo, el acuerdo favorable en tal sentido por las Administraciones constituyentes ${ }^{41}$. Así ocurre, por ejemplo, en la Ley 22/1998, de 30 de diciembre, de la Carta Municipal de Barcelona, que prevé en su artículo 61.7 la creación de los consorcios de Vivienda, de Servicios Sociales y de Educación entre la Generalitat y el Ayuntamiento de Barcelona. En este caso, la propuesta de creación es consecuencia de la voluntad expresada por el propio Ayuntamiento de Barcelona y de la propuesta de la Comisión Mixta (Generalitat-Ayuntamiento de Barcelona) prevista en la disposición transitoria primera de la Ley 8/1987, de 15 de abril, municipal y de régimen local de Cataluña.

40 Vid. por todos, Fernández Farreres G.(1993) «Las Conferencias Sectoriales y los consorcios en las relaciones de colaboración entre el Estado y las Comunidades Autónomas» en Las relaciones interadministrativas de cooperación y colaboración. Barcelona: Instituto de Estudios Autonómicos, pp. 56-57.

41 El Tribunal Supremo, en su Sentencia de 21 de noviembre de 1990, mantiene el carácter voluntario de esta fórmula de colaboración interadministrativa, al señalar que «conviene, en este sentido, tener en cuenta que, cuando de lo que, en concreto, se trata es de convenir o consorciar el modo de gestionar servicios o intereses que sean comunes, en este caso a las Entidades Locales y a las Autonómicas, naturalmente que, por encontrarnos ante una relación jurídico-administrativa de carácter bi o plurilateral, ninguna de las partes puede unilateralmente establecer normas de actuación que obliguen a la otra u otras, y es por ello que lo que tal precepto da por supuesta -artículo 57 de la LRBL- ante todo, la voluntad de los entes para consorciarse o convenirse, exigiendo consiguientemente la suscripción de consorcios o convenios, con in-

194 dudable posibilidad de que quienes intervengan fijen de común acuerdo los casos, condiciones, concreción de fines y circunstancias en que la cooperación o colaboración va a prestarse recíprocamente (...)». 


\section{Heterogeneidad en su composición}

En esencia, el consorcio autonómico, al igual que el resto de consorcios interadministrativos, ha de estar integrado por Administraciones de distinto nivel. Así se desprende de la dicción literal de los artículos 57 LBRL y 6.5 de la LAP42.

Si bien es cierto que algunas leyes autonómicas, como la Ley 5/1997, de 22 de julio, de Administración Local de Galicia, posibilitan la constitución de consorcios locales puros ${ }^{43}$, lo cierto es que la constitución de un ente asociativo integrado por administraciones del mismo nivel y grado, en particular municipios, no debería adquirir una forma consorcial, puesto que la asociación voluntaria de dos o más municipios para la ejecución en común de obras y servicios determinados de su competencia constituye, de conformidad con la legislación básica de régimen local, una mancomunidad de municipios ${ }^{44}$. Por esta misma razón, el Tribunal Superior de Justicia de la Comunidad Valenciana, en su sentencia número 1378/2006, de 3 de julio considera nula la constitución del Consorcio de Aguas de L'Horta, integrado exclusivamente por ayuntamientos, al considerar que tal asociación voluntaria de municipios, dado su objeto -prestación del servicio obligatorio de suministro domiciliario de agua potable- y entes integrantes, debiera adoptar la personalidad jurídica de Mancomunidad. Así, el TSJ entiende que, tal y como se desprende del artículo 44 de la LBRL, no es válido dar forma de consorcio a lo que debiera ser una mancomunidad y no es lícito, por ello mismo, burlar el procedimiento instituido por el legislador para la constitución de este tipo de asociación voluntaria de municipios.

\section{Personalidad jurídica propia e independiente}

Igualmente, resulta inherente a la naturaleza del consorcio la personalidad jurídica propia y diferente de la de los entes que lo integran. Si no surge esta nueva personalidad, estaremos ante otras fórmulas de cooperación (como por ejemplo el convenio), pero no ante un consorcio.

En este sentido el Tribunal Supremo, desde su Sentencia de 2 de abril de 1979, ha venido manteniendo «que como con el nacimiento del Consorcio surge un nuevo

42 Vid. en el mismo sentido, Rebollo Puig, M. (1997), op. cit., pp. 204-205.

43 El artículo 149.1 de la Ley 5/1997, de 22 de julio, de Administración Local de Galicia establece que «las entidades locales gallegas podrán, con carácter voluntario, constituir consorcios locales entre sí o con otras administraciones públicas para fines de interés común o con entidades privadas sin ánimo de lucro que persigan fines de interés público concurrentes con los de las administraciones públicas».

44 Esta misma consideración mantiene el Consejo Consultivo de Andalucía en aclaración solicitada a su Dictamen número 22 del año 2001, al negar la posibilidad, en aplicación del derecho vigente, de que pueda acudirse a la fórmula consorcial allí donde quienes se asocian son exclusivamente municipios, pues, en este caso, señala el alto órgano consultivo, la entidad idónea es la mancomunidad de municipios. Sobre las diferencias entre las mancomunidades de municipios y los consorcios vid. Martínez Fernández, F (2005) "Mancomunidades y Consorcios» en Revista Gallega de Administración Pública, 34: 205-206 y Barrero Rodríguez C. (2002) op. cit., pp. 81-119. 
ente, dotado de personalidad jurídica, como ya se anticipó, del que se ha dicho que es una asociación de asociaciones, una asociación local de segundo grado, un Ente instrumental, servido por técnicas de colaboración y de articulación de competencias públicas, es obvio que las funciones o servicios a desarrollar por el mismo, a él tienen que ser imputables $y$, en ese ajuste de competencias se produzca una metamorfosis, desapareciendo las originarias de los Entes integrados, para reinar las atribuidas al Consorcio, que, por carecer de población y territorio propios, lo que en él aparece como elemento identificador es la función o servicio que haya servido de causa generatriz...».

\section{La naturaleza jurídico-pública}

La posibilidad que abre el vigente artículo 87 de la LBRL a la integración en los consorcios de entidades privadas sin ánimo de lucro que persigan fines de interés público concurrentes con los de las Administraciones Públicas, ha supuesto, en opinión de Nieto Garrido, la pérdida del carácter interadministrativo y público de los consorcios ${ }^{45}$. Sin embargo, para Martín Mateo, del hecho de que formen parte del Consorcio sujetos de Derecho privado no se derivan mayores obstáculos para que el ente resultante tenga naturaleza administrativa ${ }^{46}$. De la misma opinión es Rebollo Puig, para quien «al adoptar la condición de miembros del ente verdaderas Administraciones Públicas, el ente como tal asume indudablemente ese carácter, incluso cuando una de las consorciadas es una entidad privada el resultado sigue siendo una Administración. Sus fines siguen siendo públicos» ${ }^{47}$.

En el mismo sentido, el Tribunal Superior de Justicia de Cataluña, en su Sentencia número 458/2002, de 4 de abril, ha concluido que la naturaleza pública de un consorcio no se desvirtúa por la presencia de un ente privado en su estructura organizativa. Y ello es así porque adopta una forma jurídico-pública, (la LAP en su artículo 6.5 hace referencia, con carácter alternativo, a los consorcios y a las sociedades mercantiles); sus fines se circunscriben a la prestación de servicios o al ejercicio de competencias de interés común a las diferentes administraciones, y que el consorcio ejerce por mandato del ente matriz (actuación fiduciaria); así, el consorcio hace suyo el servicio o competencia encomendado, tratándose de una suerte de gestión directa. En definitiva, para el TSJ, opinión que comparto, la participación de entidades privadas sin ánimo de lucro no desvirtúa la naturaleza de los fines del consorcio, que deben ser «fines de interés general» concurrentes con los de las administraciones públicas participantes.

45 Nieto Garrido, E. (1997), op. cit., p. 47.

46 Martín Mateo, R. (1992), op. cit., p. 30.

47 Rebollo Puig, M. (1997), op. cit., p. 204. En el mismo sentido Martínez Beltrán, J. A. (2009) «Técnicas institucionales de colaboración público-privada: los consorcios y las sociedades de economía mixta» en La colaboración público-privada en la Ley de Contratos del Sector Público. Aspectos administrativos y financiero». Madrid: La Ley, pp. 381-401. 


\section{El carácter instrumental respecto de las administraciones consorciadas}

La instrumentalidad, si bien ha sido concebida tradicionalmente como una relación característica de los entes institucionales respecto del ente matriz, es también una característica predicable de las corporaciones interadministrativas como el Consorcio. Los caracteres que presenta la relación de instrumentalidad que une al Consorcio con los entes miembros son: en primer lugar, que el fin o los servicios en función de los cuales se constituye el consorcio caen dentro de la órbita competencial de los entes miembros, de forma que éstos se convierten en responsables políticos de la efectiva realización del fin consorcial; en segundo lugar, que en materia patrimonial el Consorcio tiene adscritos bienes aportados por los entes miembros; en tercer lugar, que sus órganos de gobierno deben estar constituidos por representantes de los entes miembros; y por último, que la mayor parte de su financiación procede igualmente de los entes miembros.

De este modo, tal y como ha afirmado Rebollo Puig, aunque se dé la notable y relevante peculiaridad de que no hay una única Administración fundadora, sino que, varias Administraciones Públicas realizan el papel de entidades matrices para crear entre todas ellas una sola entidad institucional, el consorcio ha de calificarse como Administración instrumental ${ }^{48}$. De modo que, aunque la dependencia del consorcio respecto de cada una de las entidades matrices es menor, tal circunstancia no es suficiente para negar esta naturaleza de ente instrumental.

Esto no significa, sin embargo, que los consorcios tengan la naturaleza de entes dependientes de todas y cada una de las Administraciones que lo integran, puesto que la dependencia sólo puede predicarse del ente a quien se adscriben, sino que están «vinculados» a ellas por una relación de instrumentalidad que, entre otras cosas: posibilita la adscripción de personal funcionario o laboral de las Administraciones consorciadas; permite, a los efectos de lo previsto en el artículo 24.6 de la Ley 30/2007, de 30 de octubre, de Contratos del Sector Público (LCSP) considerar al consorcio como medio propio e instrumental de cada una de las administraciones consorciadas ${ }^{49} ; \mathrm{y}$, por último, permite, de conformidad con la normativa reguladora de las subvenciones (Ley 38/2003, de 17 de noviembre, General de Subvenciones), excluir del

48 Rebollo Puig, M (1997) op. cit. págs 203 y ss.

Así lo ha entendido también, de forma indirecta, el Tribunal de Justicia de las Comunidades Europeas, quien, ante un supuesto similar -una sociedad cooperativa municipal controlada exclusivamente por diversas autoridades públicas representativas de diversos entes-, ha entendido que todas ellas ejercen sobre la sociedad conjuntamente un control análogo al que ejercen sobre sus servicios. Cfr. STJCE de 13 de noviembre de 2008, Asunto C-324/07, Coditel Brabant SPRL contra Commune d'Uccle Règion de BruxellesCapitale.

49 A estos efectos, y según la jurisprudencia del TJCE, no será obligatoria la apertura de un proceso de licitación, aunque la otra parte contratante sea una persona jurídicamente distinta del poder adjudicador, cuando se cumplan, con carácter acumulativo, estos dos requisitos: por una parte, la autoridad pública que actúa como entidad adjudicadora debe ejercer sobre la persona distinta de que se trate un control análogo al que ejerce sobre sus propios servicios y, por otra parte, dicha persona debe realizar la parte esencial de su actividad con el ente o entes públicos que la controlan. 
ámbito de aplicación de las referidas normas las aportaciones dinerarias que la Administración autonómica realice al consorcio para financiar globalmente su actividad ${ }^{50}$.

$$
\text { Es esta, por lo demás, una posición avalada por una reiterada jurisprudencia51. }
$$

\section{Posición de dominio de la Administración autonómica}

Por último, como se ha venido reiterando, la característica determinante de la naturaleza autonómica del ente consorcial vendrá dada por la posición de dominio que la Administración autonómica o los demás entes integrantes del sector público autonómico ejerzan sobre el mismo. Así, y como se ha propuesto en el apartado precedente, la posición de dominio se medirá tanto en términos de control financiero y de control orgánico. Éste será pues el criterio determinante de la integración de un consorcio en el ámbito del sector público autonómico y, en consecuencia, de su sometimiento al régimen jurídico básico que resulte de aplicación en la Comunidad Autónoma de que se trate.

De los más recientes pronunciamientos del TJCE sobre esta cuestión -STJCE asunto C-295/05, conocido como asunto Tragsa o STJCE de 11 de mayo de 2006, Asunto C-340/04 (Carbotermo SPA y Consorzio Alisei contra Comune di Busto Arsizio y AGESP SpA)-, se pueden sacar las siguientes conclusiones: Primera, que cuando se trata de entes públicos cabe la posibilidad de considerar a todos ellos entes dominantes respecto de un mismo ente instrumental; Segunda, que el tamaño de la participación de una corporación pública individual en una sociedad o ente de derecho público formado por diversas corporaciones públicas, no sirve, por si solo, para determinar la facultad de control de un ente, pudiendo considerar que la participación con un $0,25 \%$ del capital social de una sociedad (Tragsa) es suficiente para entender que dicha sociedad no puede tener la consideración de tercero respecto de la corporación pública titular de las acciones; Tercera, que el control análogo sobre una sociedad o ente puede ser ejercido conjuntamente por diversas corporaciones públicas; Cuarta, que la consideración de que una sociedad o ente realiza la parte esencial de su actividad con un ente matriz, puede entenderse cumplido, si dicha actividad se desarrolla conjuntamente con varias corporaciones públicas, si todas ellas participan en el ente. En consecuencia, la consideración de medio propio y servicio técnico del consorcio autonómico respecto de la Administración autonómica resulta clara, pues ésta, en base a la posición de dominio ejercida en los órganos de gobierno del ente consorcial, ostenta sobre el mismo un poder análogo al que ejerce sobre sus propios servicios. En todo caso, y por prescripción de la propia LCSP, tal condición habrá de ser reconocida, con carácter expreso, en la norma estatutaria, que deberá precisar igualmente el régimen de las encomiendas que las administraciones integrantes del consorcio le puedan conferir.

50 Vid. a estos efectos, el artículo 2.2 de la Ley 38/2003, de 17 de noviembre, precepto de carácter básico ex Disposición final primera, según el cual «no están comprendidas en el ámbito de aplicación de esta Ley las aportaciones dinerarias entre diferentes Administraciones públicas, para financiar globalmente la actividad de la Administración a la que vayan destinadas, y las que se realicen entre los distintos agentes de una Administración cuyos presupuestos se integren en los Presupuestos Generales de la Administración a la que pertenezcan, tanto si se destinan a financiar globalmente su actividad como a la realización de actuaciones concretas a desarrollar en el marco de las funciones que tenga atribuidas, siempre que no resulten de una convocatoria pública». Más explícita resulta la Ley 9/2007, de 13 de junio, de subvenciones de Galicia, que excluye igualmente de su ámbito de aplicación, en su artículo 2.2 c) las aportaciones dinerarias a favor de otras administraciones y a favor de organismos y entidades dependientes de la Administración de la Comunidad Autónoma sometidos al ordenamiento autonómico destinadas a financiar global o parcialmente su actividad con carácter indiferenciado.

51 STS de 2 de abril de 1979 y, más recientemente, las STSJ de Madrid de 2 octubre de 2007 o STSJ de Baleares de 27 de marzo de 2008. 


\section{UNA APROXIMACIÓN AL RÉGIMEN DE CONTRATACIÓN Y DE PERSONAL DE LOS CONSORCIOS AUTONÓMICOS}

Teniendo en cuenta la naturaleza de ente de derecho público del consorcio interadministrativo, su sometimiento al derecho público es un requisito que permanece inalterable, sea cual fuere su naturaleza jurídica. No así su sujeción a la legislación local, autonómica o estatal.

En consecuencia, el régimen derivado de la normativa administrativa general resulta íntegramente aplicable a la totalidad de consorcios interadministrativos; así, el régimen jurídico, procedimiento administrativo, normativa básica reguladora de la función pública, contratación administrativa, el patrimonio de las respectivas Administraciones Públicas, la formación de los presupuestos, etc.

La integración de un consorcio en el sector público autonómico -medida en términos de la posición de dominio (orgánico y/o financiero) ejercida por la Administración autonómica en el ámbito del consorcio-, que será determinante, además, de su naturaleza jurídica autonómica, implicará el sometimiento de aquél, en su actividad y funcionamiento ordinarios, al ordenamiento jurídico de la Administración autonómica a que se adscriba.

Sin embargo, el alcance de la adscripción de un consorcio al ente público dominante, por su composición heterogénea, no puede tener la misma intensidad que el resto de entes instrumentales respecto de la administración matriz (Agencias u Organismos Autónomos). Es por ello que en este aspecto, los estatutos del consorcio jugarán un papel fundamental a la hora de determinar las particularidades que, respecto de la normativa marco de general aplicación en el ámbito del sector público autonómico, presentarán los consorcios en los aspectos organizativos, funcionales y financieros.

En efecto, ante la imposibilidad de establecer una regulación unitaria del régimen jurídico de los consorcios, dada su peculiar naturaleza, tanto la normativa reguladora en materia de régimen local (artículo 110 del Real Decreto Legislativo 781/1986, de 18 de abril, por el que se aprueba el Texto Refundido de las Disposiciones Legales Vigentes en materia de Régimen Local) como la Ley 30/1992, de 26 de noviembre, de Régimen Jurídico de las Administraciones Públicas y del Procedimiento Administrativo Común, encomiendan a los estatutos el establecimiento de las particularidades del régimen orgánico, funcional y financiero del Consorcio de que se trate.

Ahora bien, ¿qué alcance puede tener la norma estatutaria en la reglamentación de dichas particularidades respecto del régimen general?, o dicho de otro modo, ¿en qué materias los estatutos pueden desarrollar un régimen propio y diferente al previsto en la normativa autonómica que resulte de aplicación?

En mi opinión, lo que la Ley encomienda a los estatutos no es la regulación de la totalidad del régimen jurídico de los consorcios (de ahí la necesidad de determi- 
nar su naturaleza jurídica), sino simplemente de las particularidades del mismo. De esta forma, el régimen propio de los consorcios autonómicos no puede resultar radicalmente distinto de aquél al que está sujeta la Administración autonómica. Así, las particularidades no autorizan a que el consorcio carezca de fiscalización previa, tampoco autorizan a seguir procedimientos de adjudicación contractual que contraríen los establecidos para las Administraciones públicas. Autorizan, en cambio, a que se definan los órganos de fiscalización, a que se determine la composición de las mesas de contratación, a que se regule el régimen del personal que preste sus servicios en el organismo, y ello siempre que la normativa de aplicación (en este caso la normativa autonómica) no aborde una reglamentación en tal sentido.

En definitiva, corresponderá a los estatutos la regulación de aquellas cuestiones que, de aplicarse la normativa general y, en especial, la reglamentaria, serían de imposible cumplimiento por la falta de equiparación entre las categorías de alguna o de todas las Administraciones consorciadas con la propia Administración del consorcio.

Teniendo en cuenta que el tratamiento del régimen jurídico de los consorcios de naturaleza autonómica exigiría, dada la disparidad de reglamentaciones vigente, un exhaustivo análisis del régimen organizativo y de funcionamiento de los consorcios existentes, simplemente abordaré, de forma sucinta, algunas de las cuestiones que han suscitado mayor controversia en relación con su régimen de contratación y de personal.

\section{Régimen de contratación}

La LCSP incluye, en su ámbito de aplicación subjetivo, a los consorcios dotados de personalidad jurídica propia. De acuerdo con lo previsto en su artículo 3.1.e) «los consorcios dotados de personalidad jurídica los que se refieren el artículo 6.5 de la Ley 30/1992, de 26 de noviembre, de Régimen Jurídico de las Administraciones Públicas y del Procedimiento Administrativo Común, y la legislación de régimen local» forman parte del sector público.

Ahora bien, para determinar el grado de intensidad de aplicación de la misma, el artículo 3 de la LCSP, en sus apartados 2 y 3, distingue entre «administraciones públicas», a quienes se aplicará íntegramente el contenido de la ley y «poderes adjudicadores que no tienen la consideración de administraciones públicas», a quienes sólo se le aplican determinadas normas de la misma. Al no mencionar expresamente a los consorcios en ninguno de estos apartados, se ha planteado la duda de qué consideración deben tener los consorcios y, en consecuencia, con qué intensidad se les han de aplicar los preceptos de la ley y qué régimen jurídico tendrán los contratos 200 por ellos celebrados. 
Para Gimeno Feliu el elemento clave es el apartado e) del artículo 3.252, cuyo análisis, según el referido autor, nos lleva a la conclusión de que los consorcios (al igual que las Agencias Públicas), cuando cumplan alguno de los dos requisitos previstos en el mismo, tendrán la consideración de Administración pública y estarán sometidos a las prescripciones de la LSCP en todo caso, tanto en fase de preparación y adjudicación como de cumplimiento y extinción ${ }^{53}$.

La Junta Consultiva de Contratación Administrativa, en su Informe 38/2008, de 31 de marzo de 2009, ha dado un paso más en esta línea al concluir que los consorcios son considerados administraciones públicas y, en consecuencia, deberán aplicar las previsiones de la LCSP en su más alto grado de intensidad (preparación, adjudicación, efectos y extinción). En consecuencia, únicamente restaría a los estatutos la posibilidad de establecer aquellas particularidades de índole organizativa que consideren pertinentes (así, en la determinación del órgano de contratación, en la composición de las mesas de contratación, etc). La rotundidad del Informe queda de manifiesto en los siguientes párrafos:

«la Ley de Contratos del Sector Público señala, en su artículo 3.1 e), que forman parte del sector público los consorcios dotados de personalidad jurídica propia a los que se refieren el artículo 6.5 de la Ley 30/1992, de 26 de noviembre, de Régimen jurídico de las Administraciones Públicas y del procedimiento administrativo común, y la legislación de régimen local, distinguiéndolos de las Administraciones Públicas enumeradas en la letra a) del mismo precepto (Administración General del Estado, de las Comunidades Autónomas y entidades que integran la administración local). Más adelante, en su apartado 2, efectúa una distinción en el ámbito del sector público al referirse a quienes integran, a efectos de la propia Ley, las Administraciones públicas, no citando expresamente, como así debería haberse hecho, a los consorcios, lo que no impide atribuirles tal carácter por aplicación de la previsión referida al ámbito subjetivo en la letra e) en la que señala como parte de la Administración pública las entidades de derecho público vinculadas a una o varias Administraciones públicas o dependientes de las mismas que cumplan alguna de las características siguientes: que su actividad principal no consista en la producción en régimen de mercado de bienes y servicios destinados al consumo individual o colectivo, o que efectúen operaciones de redistribución de la renta y de la riqueza nacional, en todo caso sin ánimo de lucro, lo que es lo mismo que advertir que realicen funciones de interés general que no tienen carácter mercantil o industrial, es decir desarrollo de una función pública, o que no se financien mayoritariamente con in-

52 El artículo 3.2.e) de la LCSP establece lo siguiente «Dentro del sector público, y a los efectos de esta Ley, tendrán la consideración de Administraciones Públicas, los siguientes entes, organismos y entidades: (...) e) las entidades de derecho público vinculadas a una o varias Administraciones Públicas o dependientes de las mismas que cumplan alguna de las características siguientes: $10^{\text {a }}$ que su actividad principal no consista en la producción en régimen de mercado de bienes y servicios destinados al consumo individual o colectivo, o que efectúen operaciones de redistribución de la renta y de la riqueza nacional, en todo caso sin ánimo de lucro, o 2. ${ }^{a}$ que no se financien mayoritariamente con ingresos, cualquiera que sea su naturaleza, obtenidos como contrapartida a la entrega de bienes o a la prestación de servicios».

53 Gimeno Feliu (2008) «El nuevo ámbito subjetivo de aplicación de la Ley de Contratos del Sector Público». Revista de Administración Pública, 176, p. 45. 
gresos, cualquiera que sea su naturaleza, obtenidos como contrapartida a la entrega de bienes o a la prestación de servicios, lo que es lo mismo que indicar que se financien con fondos públicos o que procedan de la Administración.

De cuanto antecede se ha de estimar que los consorcios se configuran como una extensión de las Administraciones Públicas cuando sean creados para el desarrollo de cuestiones y servicios de interés común, lo que implica que, como continuación de las mismas, tendrán su misma consideración al ejercer en el ámbito administrativo una función que es propia de los órganos que lo crean cuyo fin es la gestión de servicios».

\section{Régimen de personal}

El artículo 2.1 de la Ley 7/2007, de 12 de abril, del Estatuto Básico del Empleado Público establece que las previsiones contenidas en ella resultarán de aplicación, además de a la Administración General del Estado, Administraciones de las Comunidades Autónomas y de las Ciudades de Ceuta y Melilla, Administraciones de las entidades locales, Universidades Públicas, Organismos Públicos, Agencias, a las demás entidades de derecho público con personalidad jurídica propia, vinculadas o dependientes de cualquiera de las Administraciones Públicas.

Teniendo en cuenta la naturaleza de ente de derecho público, vinculado o dependiente de las administraciones públicas que tienen los consorcios, no cabe la menor duda que las normas previstas en el EBEP resultan de aplicación a estos entes ${ }^{54}$.

Así, el ejercicio de las funciones que impliquen participación directa o indirecta en el ejercicio de potestades públicas o en la salvaguarda de los intereses del consorcio, corresponderá, en exclusiva, al personal sujeto al estatuto funcionarial, debiendo observar la norma estatutaria las determinaciones que sobre las previsiones contenidas en el artículo 9.2 del EBEP establece la normativa autonómica de desarrollo.

Es esta una cuestión de cierta importancia, por cuanto se ha planteado la duda de si los Consorcios pueden tener personal funcionario propio.

En mi opinión, nada obsta para que los Consorcios, en tanto que entidades con personalidad jurídica propia, puedan disponer de personal propio y asumir la gestión

54 Así los hemos caracterizado y así los han reconocido los tribunales y, como hemos visto, la propia JCCA, quien en su Informe 38/2008, de 31 de marzo de 2009, incluye a los consorcios, a los efectos del ámbito de aplicación de la Ley de Contratos del Sector Público, en el concepto de Entidades de derecho público vinculadas a una o varias Administraciones Públicas o dependientes de las mismas que cumplan alguna de las características siguientes: 1) que su actividad principal no consista en la producción en régimen de mercado de bienes y servicios destinados al consumo individual o colectivo, o que efectúen operaciones de redistribución de la renta y de la riqueza nacional, en todo caso sin ánimo de lucro, o 2) que no se financien mayoritariamente con ingresos, cualquiera que sea su naturaleza, obtenidos como contrapartida a la entrega de bienes o a la prestación de servicios. 
del mismo. Así, la plantilla o la relación de puestos de trabajo del consorcio podrá estar integrada por personal funcionario y/o laboral. En todo caso, conviene tener presente que una decisión de tal naturaleza debe venir condicionada, fundamentalmente, tanto por el carácter contingente del objeto del consorcio, como por la necesidad de que los Estatutos prevean de forma explícita y precisa el destino de su personal en caso de disolución.

No obstante lo anterior, con base en la relación de instrumentalidad que une al consorcio con las Administraciones que lo integran, será posible la adscripción al consorcio autonómico del personal funcionario o laboral procedente de cualquiera de las Administraciones consorciadas. Una decisión prudente y aconsejable, sobre todo en aquellos casos en que, bien sea por el carácter contingente de sus fines o por cualquier otra razón, las administraciones consorciadas duden del carácter indefinido o duradero del mismo. Es más, es ésta una solución que en términos técnicos plantea menores problemas en el momento de la disolución del Consorcio.

En cuanto a la situación administrativa en la que quedaría dicho personal respecto de su administración de procedencia han sido varias las soluciones propuestas.

La normativa andaluza de régimen local soluciona este problema al prever en una norma con rango de Ley (artículo 41 de la Ley 7/1993, de 27 de julio, de Demarcación Municipal) el régimen del personal transferido a los consorcios creados a su amparo. Así, los consorcios podrán contar con funcionarios transferidos (o que voluntariamente acepten su adscripción), en cuyo caso quedan adscritos a los servicios traspasados, quedando en situación de servicio activo en la Administración de procedencia y en calidad de comisión de servicios en el organismo o entidad al que el servicio se adscribió, con respeto de todos sus derechos. Recibirán sus retribuciones por este mismo organismo y dicha situación de comisión de servicios se extenderá por el tiempo previsto en la normativa constitutiva del nuevo organismo y, en su caso, carácter indefinido.

A falta de normativa autonómica aplicable, y teniendo en cuenta que, técnicamente, no existirían funcionarios del consorcio, sino funcionarios de las Administraciones que lo integran, éstos continuarán en la situación de servicio activo en la Administración de procedencia, debiendo cubrirse los puestos de que se trate a través de las diferentes formas de provisión previstas en la normativa aplicable a las Administraciones consorciadas. 
